\title{
Asian stock markets, US economic policy uncertainty and US macro-shocks
}

\section{Michael Donadelli}

To cite this article: Michael Donadelli (2015) Asian stock markets, US economic policy uncertainty and US macro-shocks, New Zealand Economic Papers, 49:2, 103-133, DOI: 10.1080/00779954.2014.890024

To link to this article: http://dx.doi.org/10.1080/00779954.2014.890024

曲 Published online: 28 Feb 2014.

Submit your article to this journal $₫$

Џlll Article views: 133

Q View related articles $\widetilde{ }$

View Crossmark data \lceil

4 Citing articles: 2 View citing articles 진 


\title{
Asian stock markets, US economic policy uncertainty and US macro-shocks
}

\author{
Michael Donadelli* \\ Center of Excellence SAFE, Goethe University, Frankfurt, Germany
}

(Received 22 August 2013; accepted 22 January 2014)

\begin{abstract}
This paper studies the relationship between changes in the US macroeconomic conditions and the excess return of 10 Asian stock markets (China, India, Indonesia, Korea, Malaysia, Pakistan, Philippines, Sri Lanka, Taiwan, Thailand). My main empirical findings are as follows. First, I find no evidence of a causal relationship (in Granger's sense) between macroeconomic conditions in the US and Asian stock market excess returns. Second, in a vector autoregressive (VAR) framework, I find that bull Asian stock markets reduce US economic policy uncertainty. Last, I show that negative US credit and industrial production uncertainty shocks, and positive US stock market volatility shocks have generated a short-run drop in Asian stock markets' performances in the post-subprime crisis era.
\end{abstract}

Keywords: Asia stock markets; excess returns; economic policy uncertainty; rare events

JEL: F62 G10, G15

\section{Introduction}

Asian stock markets have provided a relatively high risk-return performance for many years. The equity risk premium (ERP) in Asian stock markets is significantly higher than the ERP in the US stock market or other developed stock markets (Donadelli \& Persha, 2014; Donadelli \& Prosperi, 2012; Grootveld \& Salomons, 2003, among others). This 'performance gap' is, on average, higher over the period 2002-2012 (i.e. post-Asian crisis period), a period of increasing economic and financial integration. ${ }^{1}$ Therefore, the ERP in Asian stock markets and the US ERP have followed different paths during the last two decades (Donadelli, 2013; Donadelli \& Persha, 2013; Grootveld \& Salomons, 2003; Jagannathan, McGrattan, \& Scherbina, 2000). Existing empirical findings suggest that the 'performance gap' might be generated by the lack in the level of financial and economic integration. In other words, international investors ask for an extra premium because Asian stock markets are affected by local/regional shocks (Donadelli \& Prosperi, 2012; Harvey, 1995). However, the 2008-2009 global demand collapse has heavily affected Asian stock markets' performances (Donadelli, 2013). ${ }^{2}$ Given the current debate on whether or not Asian stock markets are fully integrated, we ask the following question: Do changes or uncertainty shocks in US fundamentals affect Asian stock markets' performances? Differently from existing studies that examine the impact of domestic macroshocks on domestic national stock market prices, I focus on the relationship between changes in foreign (i.e. US) macroeconomic conditions and Asian stock market returns as

*Email: Donadelli@em.uni-frankfurt.de, michael.donadelli@gmail.com 
well as on the impact of US uncertainty shocks (or rare events) on Asian stock market prices. ${ }^{3}$ In addition, I examine the impact of Asian stock market shocks on the level of economic policy uncertainty in the United States. The main objective of this study, therefore, is threefold: (1) testing whether there is a causal relationship between the US macroeconomic variables and the excess return of 10 Asian national stock markets (China, India, Indonesia, Korea, Malaysia, Pakistan, Philippines, Sri Lanka, Taiwan and Thailand); (2) investigating whether Asian stock market shocks affect the level of economic policy uncertainty in the United States; and (3) investigating whether rare events in the US credit, real and financial sectors have affected Asian stock market performances in the post-subprime crisis (hereinafter post-crisis) period. ${ }^{4}$ The analysis is of general interest and motivated by several factors. First, it may have implications for international portfolio diversification strategies. In particular, it allows to understand whether or not a portfolio composed by leading Asian stock market indexes is affected by changes in the US fundamentals as well as by rare events (i.e. uncertainty shocks) either in the short run or in the long run. This is key in the portfolio construction process. Second, it may have policy implications. In particular, an analysis on the order of magnitude and duration of the impact produced by a shock in the Asian stock market on the level of macroeconomic policy uncertainty might affect policymakers' actions.

The analysis developed in this paper extends previous empirical studies in three main directions. First, it employs a novel set of key US economic indicators. In particular, I use the growth rate of the following US macroeconomic variables: consumer credit outstanding amount, industrial production and capacity utilization index, monetary base, institutional money funds, personal saving rate, consumer sentiment index, civilian unemployment rate and Chicago Board Options Exchange (CBOE) volatility index. The ultimate goal of this set of variables is to capture major movements in the US liquidity, production and stock markets. Some of the real economic measures (e.g. industrial production, monetary base, civilian unemployment rate) employed in this paper have been used by the existing literature to examine the relationship between macroeconomic variables and international stock market returns (Bilson, Brailsford, \& Hooper, 2001; Donadelli \& Prosperi, 2012; Ferson \& Harvey, 1994). In contrast, the institutional money funds, personal saving rate and consumer sentiment index are used for the first time in the international finance literature. The level of economic policy uncertainty in the United States is measured by using a newly introduced uncertainty index (Baker, Bloom, \& Davis, 2013). Third, in the spirit of Bloom (2009), it captures rare events (i.e. uncertainty shocks) in the US production, credit and stock markets via a set of 'ad hoc' shock indicators.

The main results of the paper are as follows. First, I show that there are not statistically significant linkages between changes in the US macroeconomic conditions and Asian stock market excess returns. I also find that there is no bidirectional causality between Asian stock market returns and the level of economic policy uncertainty in the United States. It turns out that US fundamentals do not explain the variation in Asian stock market excess returns. This suggests that local factors might still play a crucial role. Second, in a vector autoregressive (VAR) framework, I find that positive shocks in the Asian stock market generate a long-lasting drop in the level of US economic policy uncertainty. Last, I show that negative US credit and industrial production uncertainty shocks, and positive US stock market volatility shocks produce a short-run drop in Asian stock markets' performances.

The rest of the paper is organized as follows. Section 2 briefly reviews the literature. Section 3 describes data and provides summary statistics. Section 4 examines linkages 
between the US fundamentals and Asian stock market excess returns. Section 5 examines linkages between Asian stock market excess returns and the level of economic uncertainty in the United States. Section 6 studies the impact of US uncertainty shocks on Asian stock markets' performances. Section 7 concludes.

\section{A brief review of the literature}

The relationship between macroeconomic variables, both local and global, and stock market performances as well as the effects of local and global macroeconomic shocks on stock prices have been largely investigated. On one side, given the poor empirical record of the capital asset pricing model (CAPM) and other standard asset pricing models, a large number of empirical studies employ macroeconomic risk factors to capture the variation in international stock market returns (Bilson et al., 2001; Chen, Roll, \& Ross, 1986; Donadelli \& Prosperi, 2012; Ferson \& Harvey, 1994; Narayan \& Narayan, 2012, among many others). On the other side, following the increasing degree of co-movement between real and financial aggregates and the 'global impact' of the last two international recessions, recent studies focus on the impact of macroeconomic (or global) shocks on stock markets' performances. Rapach (2001), in a structural VAR (SVAR) framework, examines the effects of macroeconomic shocks on real stock prices in the United States. He finds that money supply, aggregate spending and aggregate supply shocks strongly affect stock prices. In a bivariate SVAR framework, Binswanger (2004) find that industrial production shocks are able to explain a small fraction of the variability in real stock prices. He focuses on the US, European and Japanese stock markets. Similarly, Araujo (2009) studies the role of macroeconomic shocks in explaining movements in real stock returns in Latin America. The author observes that the dynamics of real stock returns is largely affected by macroeconomic shocks. Daly and Fayyad (2011) empirically examine the relationship between oil price and stock market returns for five Gulf Cooperation Council (GCC) countries and two advanced economies (i.e. United Kingdom and United States). Their results suggest that the percent of variance of the stock returns explained by the oil price increases as oil prices increase. In addition, the predictive power of the price of oil for stock returns increased during the 2007-2009 crisis. Sharma and Wongbangpo (2002) study the relationship between changes in macroeconomic variables (i.e. gross national product [GNP], the consumer price index, the money supply, the interest rate and the exchange rate) and the stock price of five Asian markets (Indonesia, Malaysia, Philippines, Singapore and Thailand). They find evidence of a long- and short-term relationship between stock prices and domestic macroeconomic variables, and conclude that macroeconomic variables in these countries cause and are caused by stock prices (in Granger's sense).

While many studies have examined the impact of domestic changes in macroeconomic fundamentals on domestic stock markets, or focus on the effect of US macroeconomic shocks on European stock and bond markets (and vice verse), few studies in the international finance literature have examined the impact of changes in macroeconomic conditions across advanced economies on emerging/developing national stock markets. An exception is Narayan and Narayan (2012), who examine the impact of the US exchange rate and short-term interest rate on seven Asian stock markets over the pre-crisis (i.e. January 2001-August 2007) and post-crisis (i.e. September 2007-January 2010) periods. They find that changes in the US interest rate do not affect Asian stock markets over the crisis period. In contrast, the US exchange rate statistically affects (negatively) Asian stock returns. 
In contrast to previous empirical studies, this paper focuses only on the impact of changes in foreign (i.e. US) macroeconomic conditions on domestic (i.e. Asian) stock market prices. I employ a novel set of variables to capture changes in macroeconomic conditions in the United States, the level of economic policy uncertainty in the United States and the sequence of rare events seen in the United States during the 2007-2009 crisis. To the best of my knowledge, this is the first study aimed at examining the impact of rare events in the US real and financial activity on Asian stock markets' performances. In addition, it is the first study that examines the relationship between the level of economic policy uncertainty in the United States and the performance of the 10 leading Asian stock markets.

\section{Data description}

\subsection{Asian stock markets data}

I compute monthly national stock market returns from Morgan Stanley Capital International (MSCI) Total Return Indices (TRI) for the following Asian economies: China, India, Indonesia, Korea, Malaysia, Pakistan, Philippines, Sri Lanka, Taiwan and Thailand. The choice of this set of Asian stock markets is motivated by several factors. First, according to the International Finance Corporation (IFC) country classification, these 10 Asian countries are classified as emerging markets. This implies that they meet one of the following two criteria: (1) the country is located in a low- or medium-income level region; and (2) the country's investable market capitalization-to-GDP ratio is relatively low. Moreover, based on the IFC classification, these 10 Asian countries retain investment restrictions, a necessary condition to be classified as emerging markets. Emerging countries, as classified by IFC, are listed in Table 1.

Second, all these markets have been liberalized in the late 1980s and early 1990s. Third, the position of the US investors in these equity markets has largely increased in the early 1990s. In other words, there is evidence of structural breaks in the dynamics of the US position in the Asian stock markets over the period 1990-1995. Last, the correlation between the US stock market returns and the return of these 10 Asian stock markets has largely increased in the early 1990s. ${ }^{5}$ In addition, these Asian stock markets have received an enormous amount of attention both in the international finance literature and in the financial industry over the last two decades (i.e. after equity market liberalizations). It is worth noting that the annual average growth rate of stocks traded (measured as \% of

Table 1. IFC country classification: emerging markets.

\begin{tabular}{llllll}
\hline Africa & \multicolumn{1}{c}{ Asia } & Eastern Europe & Europe & Middle East & Latin America \\
\hline Morocco & China & Czech Republic & Greece & Egypt & Argentina \\
Nigeria & India & Hungary & Portugal & Israel & Brazil \\
South Africa & Indonesia & Poland & & Jordan & Chile \\
Zimbabwe & Korea & Russia & & Saudi Arabia & Colombia \\
& Malaysia & Slovakia & & Turkey & Mexico \\
& Pakistan & & & Peru \\
& Philippines & & & Venezuela \\
& Sri Lanka & & & \\
& Taiwan & & & \\
& Thailand & & & \\
\hline
\end{tabular}

Source: IFC (1999). 


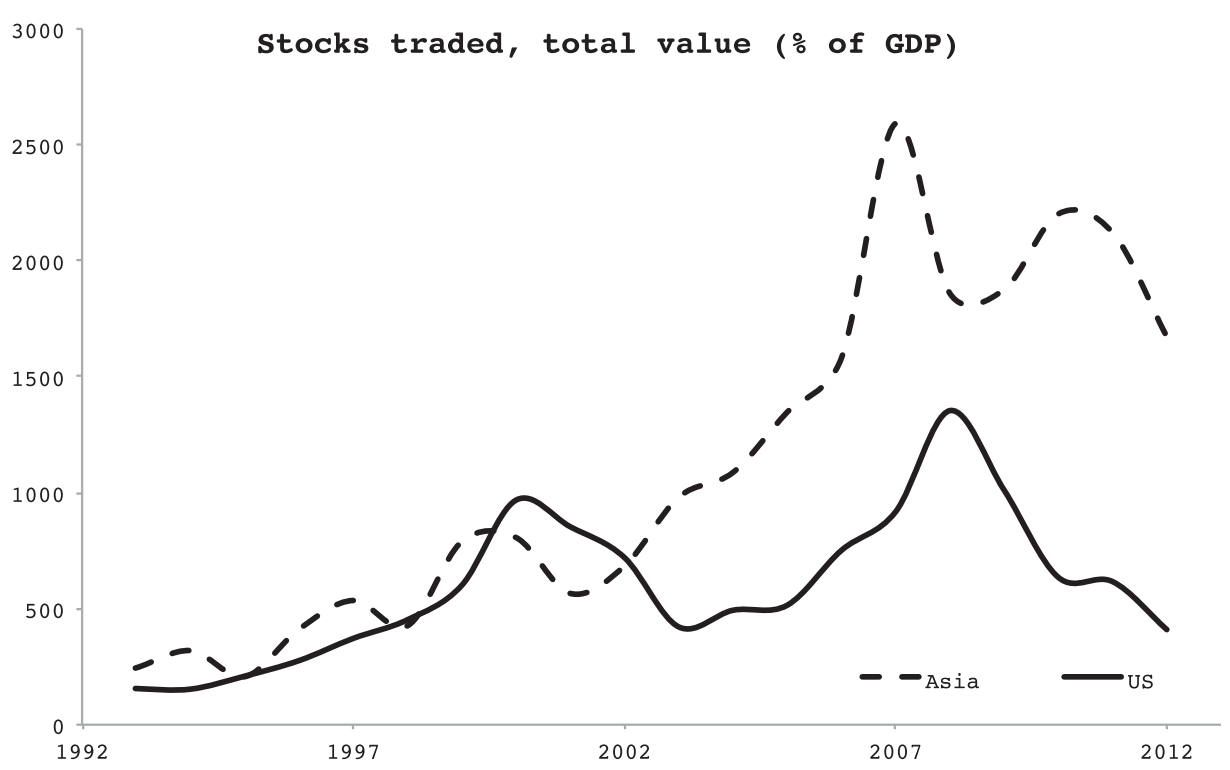

Figure 1. Stocks traded (\% of GDP).

Notes: This figure reports the cumulative growth rate of the stocks traded (measured as \% of GDP) across Asian stock markets (dashed line) and in the United States (solid line). The Asian annual average growth rate of stocks traded is the equally weighted average of the 10 Asian markets. Stocks traded refers to the total value of shares traded during the period. Sample: 1993-2012.

Source: World Development Indicators.

GDP) across the 10 Asian economies is three times larger than the US stocks traded average growth over the period 1992-2012 (i.e. 32\% vs. 11\%). This is clear from Figure 1, which plots the annual cumulative rate of change of the total value of shares traded across the 10 Asian economies (dashed line) and in the United States (solid line).

Asian total monthly returns are measured for the period January 1988 (or later)December 2011 as the capital change component of an Asian country index plus the dividend yields. ${ }^{6}$ In other words, dividends are reinvested. As standard in the literature, all returns are measured in US dollars (Bilson et al., 2001; Chambet \& Gibson, 2008; de Jong \& de Roon, 2005; Donadelli, 2013; Donadelli \& Persha, 2013; Donadelli \& Prosperi, 2012; Grootveld \& Salomons, 2003; Lee, Chen, \& Chang, 2013; Pukthuanthong $\&$ Roll, 2009). Note that returns denominated in US dollars retain only US inflation, are consistent with US macroeconomic variables' currency, and are homogeneous across Asian economies. Given that returns are measured in US dollars, excess returns are in excess of the one-month Treasury bill (T-bill) rate. Formally,

$$
Z_{i, t}=\left(\frac{M S C I T R I_{i, t}}{M S C I T R I_{i, t-1}}-1\right)-R_{t}^{f}
$$

where $Z_{i, t}$ is the excess return of country $i$ at time $t, M S C I T R I_{i, t}$ is the MSCI TRI of country $i$ at time $t$ and $R_{t}^{f}$ is the one-month T-bill rate from Ibbotson Associates. ${ }^{7}$ Monthly summary statistics for the 10 Asian stock market excess returns are presented in Table 2. Panel A reports the mean, standard deviation, skewness and kurtosis values, and the Sharpe ratio. Panel B reports the correlation between the US stock market excess return and the excess return of the 10 Asian stock markets. 


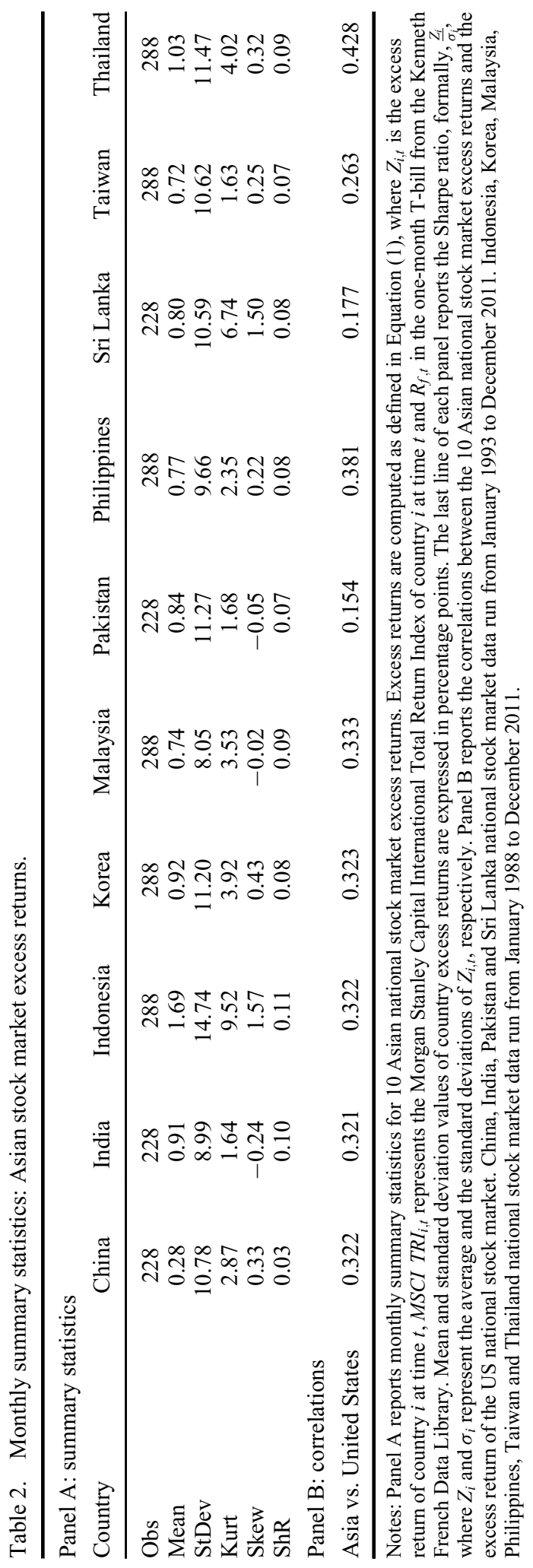




\subsection{US macroeconomic data}

To capture macroeconomic conditions in the United States, I employ seven macroeconomic variables and a stock market volatility index. The ultimate goal of this set of variables is to describe liquidity, production, and labor market conditions in the US economy. This set includes the following series: consumer credit outstanding amount (CREDIT), industrial production and capacity utilization index (INDPRO), St. Louis adjusted monetary base $(A M B S L)$, institutional money funds (IMFSL), personal saving rate (PSAVERT), consumer sentiment index (UMCSENT) and civilian unemployment rate (UNRATE). All macro-series are seasonally adjusted and provided by the St. Louis Fed economic database. The US stock market volatility is represented by the Chicago Board Options Exchange (CBOE) volatility index (VIX). The VIX is based on S\&P 500 Index Options and provided by Datastream. All employed series are monthly growth rates and run from January 1988 to December 2011. In addition, I employ the world excess return (WORLD) which is the arithmetic return on the MSCI world equity index (total return index) less the Ibbotson Associates one-month T-bill rate. To explain variation in international stock market excess returns, Ferson and Harvey (1994) and Bilson et al. (2001) employ a similar set of macroeconomic variables. The former employ the world excess return and seven global risk factors (change in Eurodollar Treasury bill, log change in G10 foreign exchange rate, unexpected G7 inflation, change in long-term G7 expected inflation, change in price of oil, change in G7 industrial production, G7 real interest rate). The latter employ the world excess return and four domestic macroeconomic variables (change in monetary base, change in goods price index, change in industrial production, change in exchange rates). To examine the relationship between the US macroeconomic fundamentals and the return of seven Asian stock markets, Narayan and Narayan (2012) use two US macroeconomic variables: (1) short-term interest rate and (2) real exchange rate. ${ }^{8}$ The US risk factors employed in this paper are chosen according to existing empirical studies on stock returns predictability and belong to a set of popular downloaded series. The world excess return is from Ferson and Harvey (1994). The changes in monetary base and industrial production are from Bilson et al. (2001). The change in the level of volatility in the US stock market is from Donadelli and Prosperi (2012). The other US macroeconomic components are chosen among the first 30 popular series listed in the 'FRED ECONOMIC DATA more popular series list'. ${ }^{9}$ I notice that this set of variables is also in line with applied works recently developed by the financial industry (e.g. hedge fund). ${ }^{10}$ Summary statistics for the US macroeconomic variables are reported in Table 3.

\section{On the role of the US macroeconomic indicators}

\subsection{Causality}

To test causality between series, I employ Granger's (1969) causality test. The idea of Granger's causality is as follows: if a variable $\Psi_{t}$ (e.g. US fundamentals) Granger-causes another variable $\Phi_{t}$ (e.g. Asian national stock market excess return), then $\Phi_{t}$ can be predicted better by using the past values of $\Psi_{t}$ than by using those of $\Phi_{t}$. Formally,

$$
\text { if } \operatorname{Pr}\left(\Phi_{t+n} \mid \Phi_{t-k}\right)=\operatorname{Pr}\left(\Phi_{t+n} \mid \Phi_{t-k}, \Psi_{t-k}\right) \Rightarrow \Psi_{t} \neq>\Phi_{t}
$$

where $\operatorname{Pr}(\cdot)$ denotes conditional probability, and $\neq>$ means 'does not Granger-cause'. The following bivariate autoregression is employed to test the causal relation between the 


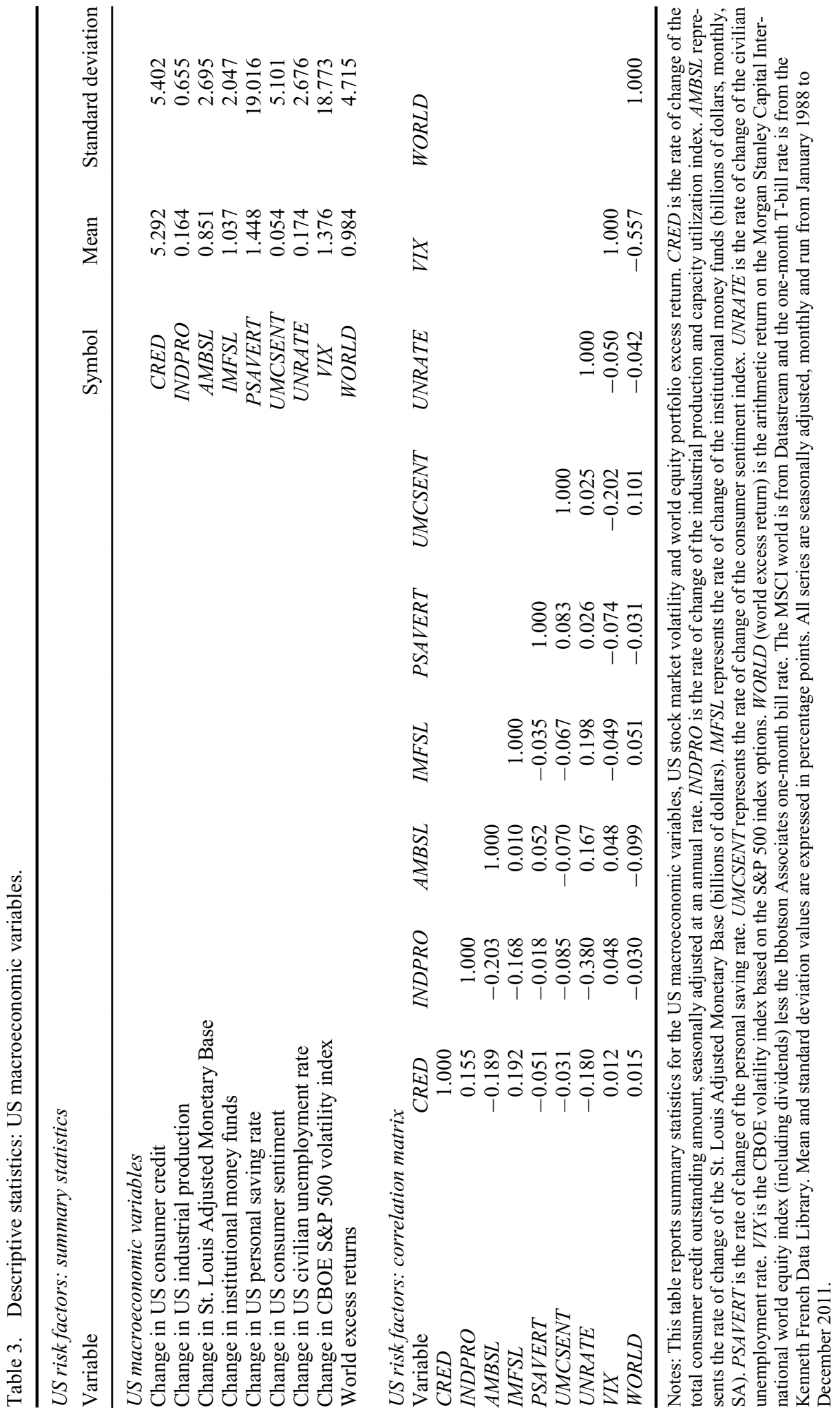


US fundamentals (i.e. $\Psi_{t}$ ) and the excess return of an Asian national stock market (i.e. $\left.\Phi_{t}\right)$ :

$$
\begin{aligned}
& \Phi_{t}=c_{\Phi}+\sum_{k=1}^{K} \Psi_{k} \Phi_{t-k}+\sum_{k=1}^{K} \delta_{k} \Psi_{t-k}+u_{\Phi, t}, \\
& \Psi_{t}=c_{\Psi}+\sum_{k=1}^{K} \alpha_{k} \Psi_{t-k}+\sum_{k=1}^{K} \beta_{k} \Phi_{t-k}+u_{\Psi, t},
\end{aligned}
$$

where $c_{\Phi}$ and $c_{\Psi}$ are constants, $\alpha_{k}, \beta_{k}, \phi_{k}$ and $\delta_{k}$ are parameters, and $u_{\Psi, t}$ and $u_{\Phi, t}$ are uncorrelated errors with zero means and finite variances. The null hypothesis that ' $\Psi_{t}$ does not Granger-cause $\Phi_{t}{ }^{\prime}$ is rejected if the $\delta_{k}$ coefficients in Equation (3) are jointly significantly different from zero. Similarly, ' $\Phi_{t}$ Granger-cause $\Psi_{t}$ ', if the $\beta_{k}$ coefficients are jointly different from zero in Equation (4). If both the $\delta_{k}$ and $\beta_{k}$ coefficients are jointly different from zero, then a bidirectional causality exists. To have non-spurious inference, the Granger-causality test requires that all series are stationary. In my empirical scheme, both financial and macroeconomic variables enter in percentage change form. This produces stationary variables. ${ }^{11}$ Table 4 reports the pairwise Granger-causality tests between the US macroeconomic variables and the 10 Asian stock market excess returns. I find no evidence for a causal relationship between changes in the US fundamentals and Asian stock market excess returns. Not surprisingly, I find that the excess return of the world equity index Granger-cause 8 out of the 10 Asian stock market excess returns. In contrast, I observe that 7 out of the 10 Asian stock markets Granger-cause the US monetary base growth rate (i.e. India, Indonesia, Korea, Philippines, Sri Lanka, Taiwan and Thailand) and the institutional money funds growth rate (i.e. India, Indonesia, Malaysia, Pakistan, Philippines, Sri Lanka and Thailand). In addition, the US stock market volatility seems to be caused (in Granger's sense) by the following Asian stock markets: India, Korea, Malaysia, Pakistan, Philippines, Sri Lanka and Thailand. Overall, entries in Table 4 suggest that changes in US macroeconomic conditions cannot be used to explain variation in Asian stock market excess returns.

\subsection{Predictability}

I briefly investigate the extent to which US macroeconomic variables are able to explain the variation in monthly Asian stock market excess returns. In particular, I examine whether a set of US economic condition indicators have explanatory power over Asian stock market excess returns in a multiple beta model context. It is largely accepted that macroeconomic variables tend to affect stock market prices with some delay (i.e. the transmission of information contained in macroeconomic variables into stock market prices might be delayed). Therefore, the model does not assume a contemporaneous association where all variables are measured at time $t$, that is, US macroeconomic variables are lagged. ${ }^{12}$ Hence, the linear multi-factor model can be written as

$$
\begin{aligned}
Z_{i, t}= & \alpha_{i}+\beta_{i, \text { WORLD }} \text { WORLD }_{t}+\beta_{i, \text { CRED }} \text { CRED }_{t-1}+\beta_{i, I N D P R O} \text { INDPRO }_{t-1} \\
& +\beta_{i, A M B S L} \text { AMBSL }_{t-1}+\beta_{i, I M F S L} \text { IMFSL }_{t-1}+\beta_{i, \text { UMCSENT }} \text { UMCSENT }_{t-1} \\
& +\beta_{i, P S A V E R T} \text { PSAVERT }_{t-1}+\beta_{i, \text { UNRATE }} \text { UNRATE }_{t-1}+V I X_{t}+u_{i, t}
\end{aligned}
$$




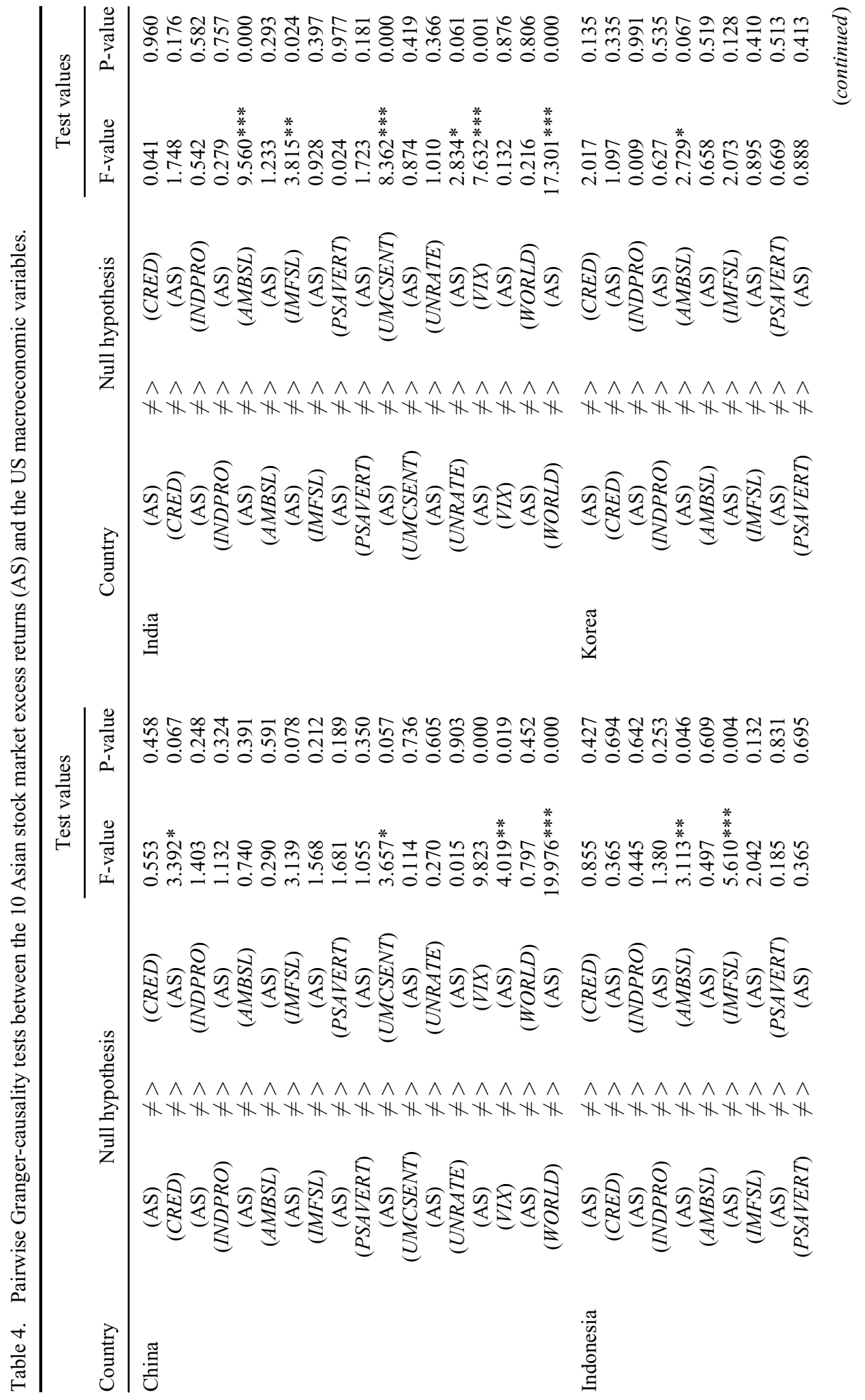




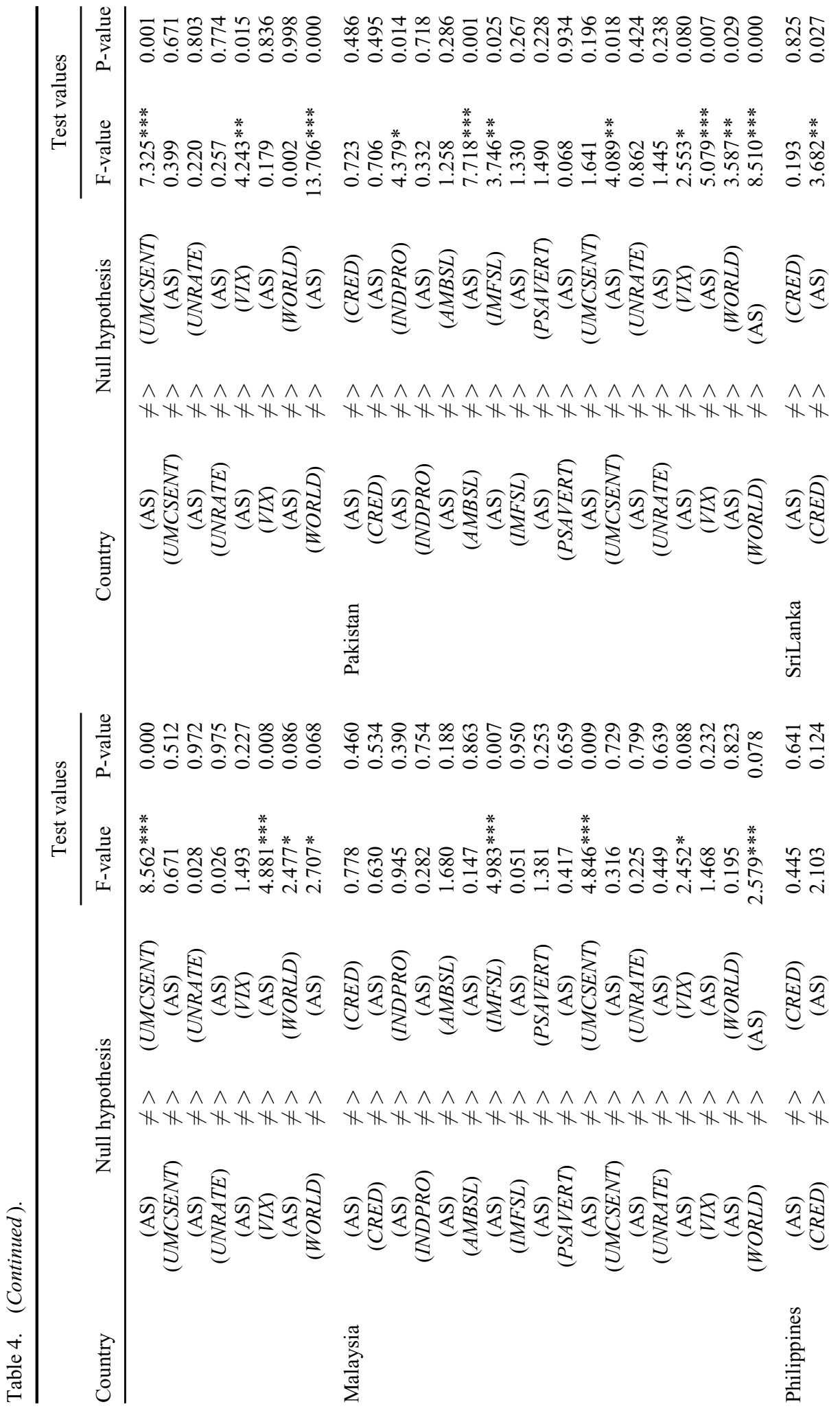




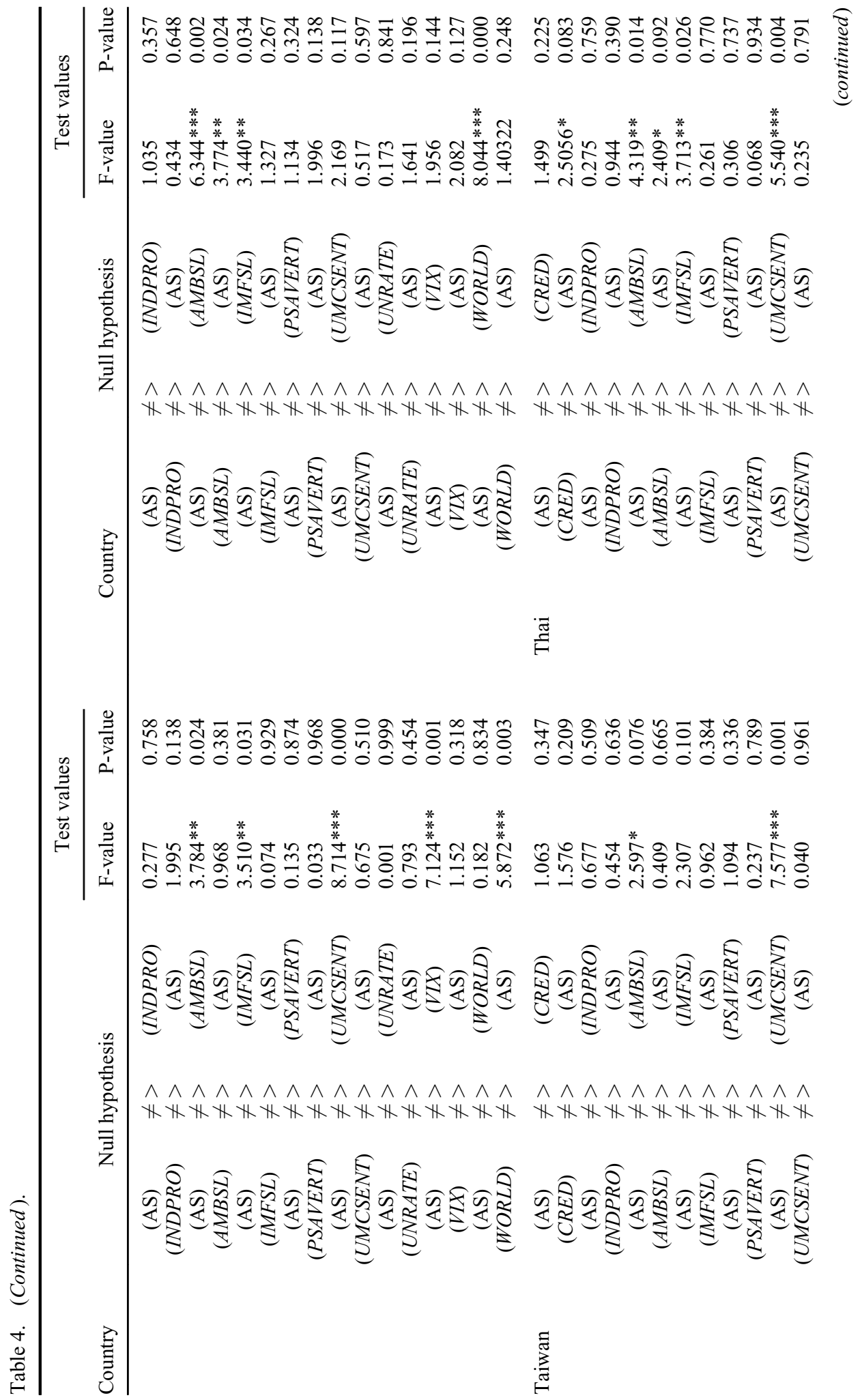




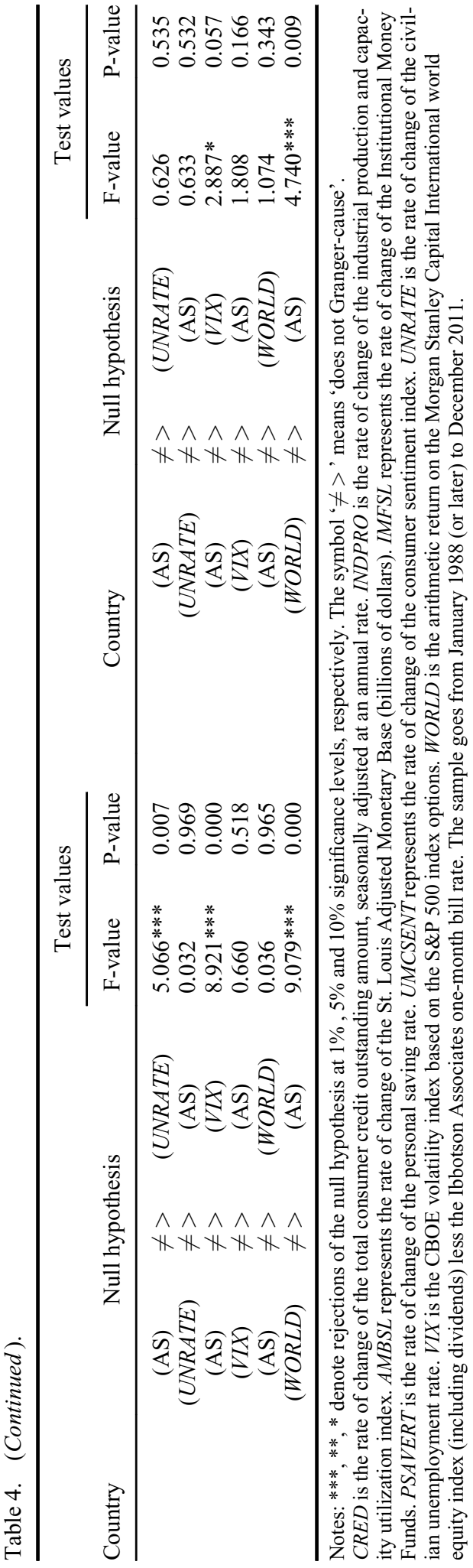


where $Z_{i, t}$ is the realized excess return for the $i$ th Asian country at time $t, W O R L D_{t}$ is the realized return on the world equity portfolio at time $t, C R E D I T_{t-1}$ is the US consumer credit growth rate at time $t-1, I N D P R O_{t-1}$ is the rate of change of the US industrial production index at time $t-1, A M B S L_{t-1}$ is the rate of change of the St. Louis Adjusted Monetary Base at time $t-1, M F S L_{t-1}$ represents the rate of change of the Institutional Money Funds at time $t-1, U M C S E N T_{t-1}$ is the rate of change of the US consumer sentiment index at $t-1, P S A V E R T_{t-1}$ is the percentage change in US personal saving rate at time $t-1, U N R A T E_{t-1}$ is the rate of change of the US civilian unemployment rate at time $t-1, V I X_{t}$ is the rate of change of the US stock market volatility index at time $t$ and $u_{i, t}$ is the innovation term. ${ }^{13}$ Equation (5) is estimated using Newey and West (1987, 1994) standard errors in an ordinary least squares (OLS) framework. Estimation results are reported in Table 5. The last two columns of the table show the $R^{2}$ for the multi-factor model and for the one-factor model (or world CAPM). Therefore, in the last column only a constant and the excess return of the world equity portfolio are included. I observe that the increment to the $R^{2}$ from including the US macroeconomic fundamentals is small. Estimation results confirm that the excess return of the world market portfolio explains the largest part of variation in monthly Asian stock market excess returns. I find that the unconditional betas of the world equity portfolio are statistically different from zero (and positive) in 7 out of the 10 Asian stock markets. Not surprisingly, the unconditional betas of VIX are statistically significant (and negative) in 5 out of the 10 Asian stock markets. ${ }^{14}$ In general, the estimation results indicate that Asian stock market excess returns show little sensitivity to US fundamentals' growth rates (consistently with the pairwise Grangercausality test results reported in Table 4). ${ }^{15}$ Overall, I find that changes in the US macroeconomic conditions weakly explain the variation in Asia stock market excess returns. ${ }^{16}$

\section{On the role of economic policy uncertainty}

\subsection{US economic policy uncertainty: a review}

The empirical strategy of this section is based on a US-based uncertainty measure that has been proposed in the recent literature on uncertainty shocks (Bloom, 2009). Specifically, I use the economic policy uncertainty index constructed by Baker et al. (2013). The index is built on the following components: (1) newspaper coverage of policy-related economic uncertainty (i.e. frequency of newspaper references to economic policy uncertainty); (2) scheduled tax code expirations; and (3) forecaster disagreement about government purchases and inflation. The first component refers mainly to economic policy decisions. Uncertainty on economic policy decisions is captured by the number of articles containing specific policy-related terms (e.g. uncertainty or uncertain, economic or economy, congress, deficit, federal reserve or FED, legislation, regulation or white house). Articles are from the following 10 large newspapers: Boston Globe, Chicago Tribune, Dallas Morning News, Los Angeles Times, Miami Herald, New York Times, San Francisco Chronicle, USA Today, Wall Street Journal and Washington Post. The second component relies on the activity of the Congressional Budget Office (CBO) that is usually uncertain about tax-cuts extensions. The third component relies on the Federal Reserve Bank of Philadelphia's Survey of Professional Forecasters (SPF) which reports forecast values for a range of variables at various horizons. Baker et al. (2013) focus only on forecast data for inflation, purchases of goods and services by the federal government, and purchases of goods and services by state and local governments, three variables that tend to be influenced by monetary and fiscal policy decisions. Forecasts are made at the individual level. 


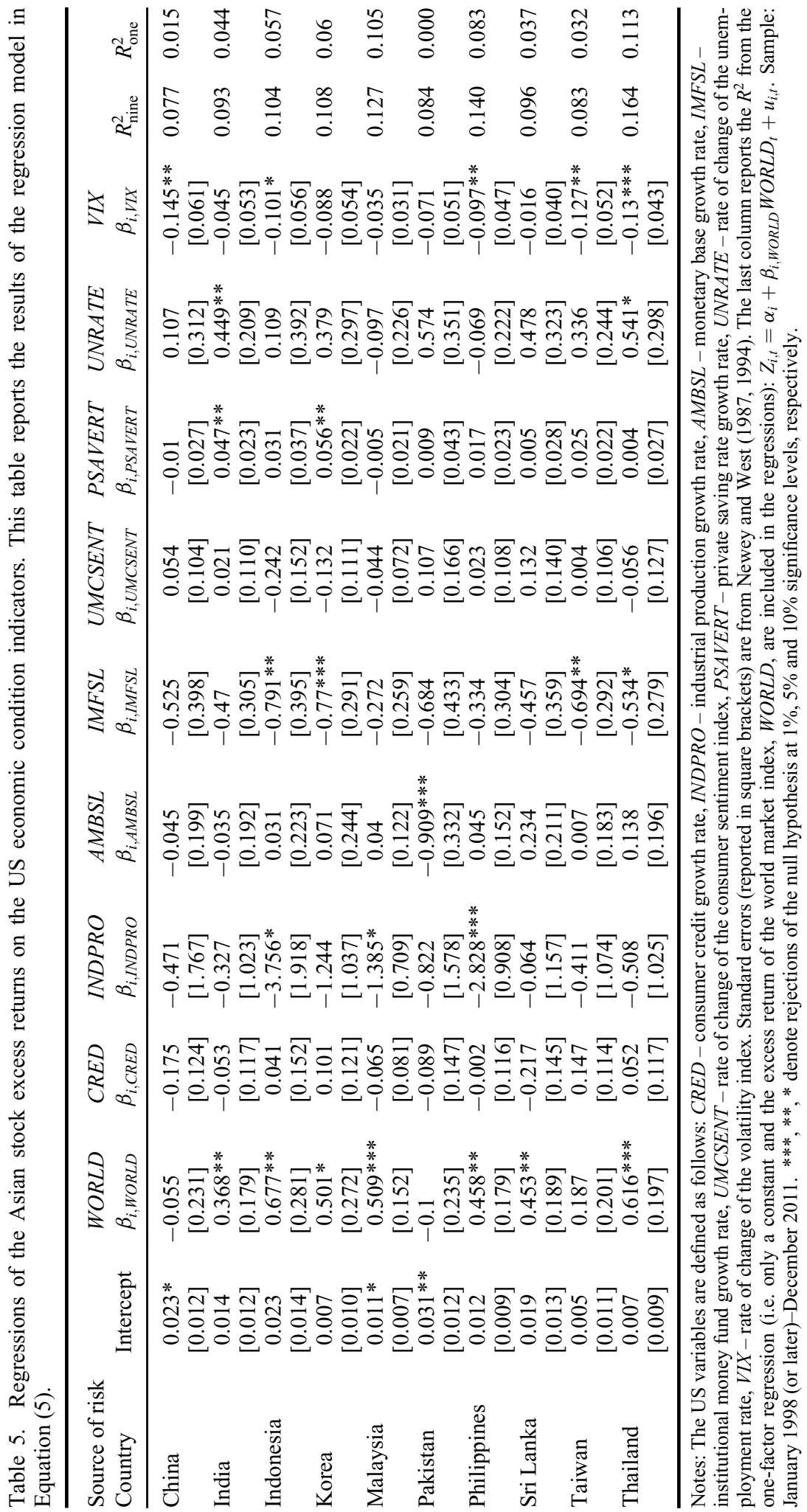


US Monthly Economic Policy Uncertainty Index

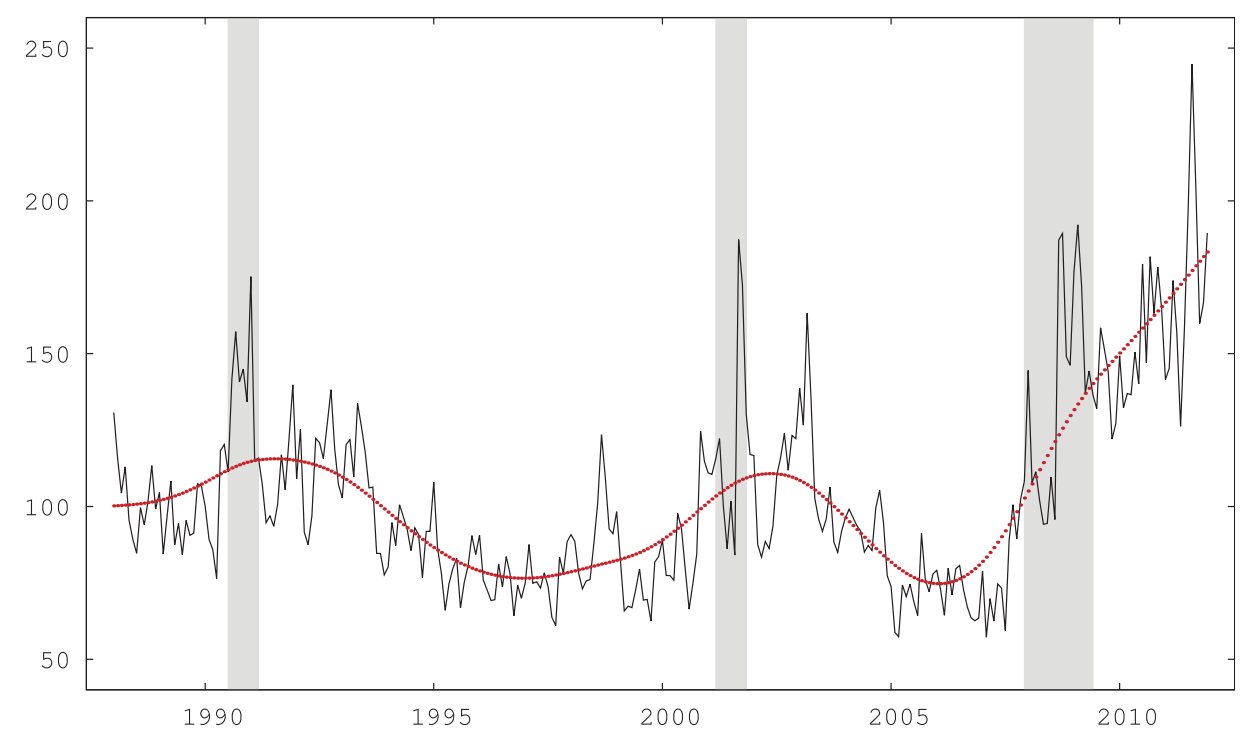

Figure 2. US macroeconomic policy uncertainty.

Notes: This figure reports the dynamics of the US monthly economic policy uncertainty index (solid black line). The smoothed red dotted line - computed using the Hodrick-Prescott filter (smoothing parameter $\lambda=14,400$ ) - represents the trend of the US monthly economic policy uncertainty index. The series is from Baker at al. (2013) and is publicly available at http://www. policyuncertainty.com/. The sample goes from January 1988 to December 2011.

In this setup, the cross-sectional dispersion of individual forecasts in the SPF data reflects uncertainty about future outcomes. ${ }^{17}$ The economic policy uncertainty index is available from 1985. Consistent with the sample analyzed in this paper, I focus on the evolution of the index over the period 1988-2011. The evolution of the US economic policy uncertainty index is reported in Figure 2. I observe that the index has followed an increasing trend over the period 2008-2012. The average level of policy uncertainty in the pre- and post-crisis era is 94.80 and 136.94, respectively. Figure 2 also suggests that the uncertainty index in the pre-crisis period is less volatile than in the post-crisis period. The volatility in the pre- and post-crisis periods is equal to $22.52 \%$ and $40.53 \%$, respectively. It turns out that the subprime crisis as well as the European sovereign debt crisis have heavily affected the level of policy uncertainty in the United States. To conclude, I stress that in the empirical analysis developed in the rest of the paper, the uncertainty index enters in a log form. The ADF test with just a constant indicates that log-uncertainty is stationary (see Table A1 in Appendix 1). From Section 4 I know that the growth rate of the Asian stock market excess returns is stationary. This implies that I can use Granger's causality test to test bidirectional causality between the uncertainty index and the excess return of the Asian stock markets (see Antonakakis, Chatziantoniou, \& Filis, 2012).

\subsection{US economic policy uncertainty vs. Asian stock markets}

\subsubsection{Causality}

In line with the analysis conducted in Section 4, I ask whether or not there is a causal relationship between the level of economic policy uncertainty in the United States and Asian 
Table 6. Pairwise Granger-causality tests between the 10 Asian stock market excess returns (AS) and the US economic policy uncertainty.

\begin{tabular}{lllr}
\hline & & \multicolumn{2}{c}{ Test values } \\
\cline { 3 - 4 } Country & Null hypothesis & F-value & P-value \\
\hline China & $(\mathrm{AS}) \neq>(E C U N)$ & $8.666^{* * *}$ & 0.000 \\
& $(E C U N) \neq>(\mathrm{AS})$ & 0.834 & 0.436 \\
India & $(\mathrm{AS}) \neq>(E C U N)$ & $6.802^{* * *}$ & 0.001 \\
& $(E C U N) \neq>(\mathrm{AS})$ & 0.119 & 0.888 \\
Indonesia & $(\mathrm{AS}) \neq>(E C U N)$ & 1.974 & 0.141 \\
& $(E C U N) \neq>(\mathrm{AS})$ & 1.819 & 0.164 \\
Korea & $(\mathrm{AS}) \neq>(E C U N)$ & $7.740^{* * *}$ & 0.001 \\
& $(E C U N) \neq>(\mathrm{AS})$ & 1.685 & 0.187 \\
Malaysia & $(\mathrm{AS}) \neq>(E C U N)$ & $2.413^{* * *}$ & 0.005 \\
& $(E C U N) \neq>(\mathrm{AS})$ & $7.369^{* * *}$ & 0.130 \\
Pakistan & $(\mathrm{AS}) \neq>(E C U N)$ & 0.299 & 0.001 \\
& $(E C U N) \neq>(\mathrm{AS})$ & $3.793^{* *}$ & 0.742 \\
Philippines & $(\mathrm{AS}) \neq>(E C U N)$ & $3.240^{* *}$ & 0.024 \\
\multirow{3}{*}{ Sri Lanka } & $(E C U N) \neq>(\mathrm{AS})$ & $\left.2.684^{*}\right)$ & 0.041 \\
& $(\mathrm{AS}) \neq>(E C U N)$ & $4.229^{* *}$ & 0.071 \\
Taiwan & $(E C U N) \neq>(\mathrm{AS})$ & $8.036^{* * *}$ & 0.016 \\
\multirow{3}{*}{ Thailand } & $(\mathrm{AS}) \neq>(E C U N)$ & 1.469 & 0.000 \\
& $(E C U N) \neq>(\mathrm{AS})$ & $3.667^{* *}$ & 0.232 \\
& $(\mathrm{AS}) \neq>(E C U N)$ & $3.556^{* *}$ & 0.027 \\
\hline
\end{tabular}

Notes: ECUN is the US economic policy uncertainty index. The sample goes from January 1988 (or later) to December 2011. ***,*** denote rejections of the null hypothesis at $1 \%, 5 \%$ and $10 \%$ significance levels, respectively. The symbol ' $\neq>$ ' means 'does not Granger-cause'.

stock markets' performances. Results from the pairwise Granger-causality tests between the excess return of the 10 Asian stock markets and the US economic policy uncertainty index are reported in Table 6 . Test values suggest that the level of economic policy uncertainty in the United States does not cause (in Granger's sense) the excess return of the following Asian stock markets: China, India, Indonesia, Korea, Malaysia, Pakistan and Taiwan. In contrast, I find that nine out of the 10 Asian stock markets Granger-cause the level of economic policy uncertainty in the United States. A bidirectional causality is found between US uncertainty and the excess return of the following three Asian stock markets: Philippines, Sri Lanka and Thailand. Overall, entries in Table 6 suggest that US uncertainty cannot be used to explain the variation in Asian stock market excess returns (consistent with results in Table 5).

\subsubsection{Predictability}

Via a standard two-factor linear model, I examine whether the level of economic policy uncertainty in the United States explains the variation in Asian national stock markets excess returns. Formally,

$$
Z_{i, t}=\alpha_{i}+\beta_{i, W O R L D} W_{\text {ORLD }}+\beta_{i, E C U N} E C U N_{t-1}+u_{i, t}
$$

where $W O R L D_{t}$ is the usual world excess return and $E C U N_{t-1}$ is the log of the US economic policy uncertainty index at time $t-1$. Estimation results are reported in Table 7. 
Table 7. Regressions of the Asian stock excess returns on the US economic economic policy uncertainty index.

\begin{tabular}{lccccc}
\hline Source of risk & & WORLD & $E C U N$ & & \\
Country & Intercept & $\beta_{i, \text { WORLD }}$ & $\beta_{i, E C U N}$ & $R_{\mathrm{two}}^{2}$ & $R_{\text {one }}^{2}$ \\
\hline China & -0.100 & 0.278 & 0.022 & 0.018 & 0.015 \\
& {$[0.127]$} & {$[0.204]$} & {$[0.027]$} & & \\
India & -0.034 & $0.376^{* * *}$ & 0.009 & 0.040 & 0.040 \\
& {$[0.100]$} & {$[0.139]$} & {$[0.022]$} & & \\
Indonesia & -0.202 & $0.745^{* * *}$ & 0.046 & 0.063 & 0.055 \\
& {$[0.134]$} & {$[0.231]$} & {$[0.029]$} & & \\
Korea & $-0.209^{*}$ & $0.583^{* * *}$ & $0.046^{*}$ & 0.073 & 0.060 \\
& {$[0.109]$} & {$[0.211]$} & {$[0.024]$} & & \\
Malaysia & 0.144 & $0.554^{* * *}$ & 0.032 & 0.115 & 0.103 \\
& {$[0.093]$} & {$[0.123]$} & {$[0.019]$} & & \\
Pakistan & -0.057 & 0.038 & 0.014 & 0.002 & 0.000 \\
& {$[0.101]$} & {$[0.182]$} & {$[0.022]$} & & \\
Philippines & $-0.243^{* *}$ & $0.596^{* * *}$ & $0.053^{* *}$ & 0.106 & 0.082 \\
\multirow{2}{*}{ Sri Lanka } & {$[0.100]$} & {$[0.169]$} & {$[0.021]$} & & \\
& -0.193027 & $0.452^{* *}$ & 0.043 & 0.055 & 0.040 \\
Taiwan & {$[0.123]$} & {$[0.187]$} & {$[0.027]$} & & \\
& $-0.178^{* *}$ & $0.398^{* *}$ & $0.039^{* *}$ & 0.042 & 0.031 \\
Thailand & {$[0.090]$} & {$[0.179]$} & {$[0.019]$} & & \\
& $-0.326^{* * *}$ & $0.832^{* * *}$ & $0.071^{* * *}$ & 0.145 & 0.114 \\
& {$[0.110]$} & {$[0.183]$} & {$[0.024]$} & & \\
\hline
\end{tabular}

Notes: This table reports the results of the regression model presented in Equation (6). ECUN is the log of the US economic policy uncertainty index. Standard errors (reported in square brackets) are from Newey and West (1987, 1994). The last column reports the $R^{2}$ from the one-factor regression (i.e. only a constant and the excess return of the world market index, WORLD, are included in the regressions): $Z_{i, t}=\alpha_{i}+\beta_{i, \text { WORLD }}$ WORLD $+u_{i, t}$. The sample goes from January 1998 (or later) to December 2011. ***, **, * denote rejections of the null hypothesis at $1 \%, 5 \%$ and $10 \%$ significance levels, respectively.

Consistently with entries in Table 5, I find that the additional risk factor reflecting economic uncertainty does not improve the model's performance in explaining the variation in excess returns across Asian stock markets. $\beta_{i, E C U N}$ is statistically different from zero only in three Asian stock markets (Philippines, Taiwan and Thailand). However, the coefficient is relatively small suggesting that an increase in uncertainty weakly increases the excess return of these stock markets. The estimation results in Table 7 also confirm that the world excess return explains the largest part of variation in Asian stock market excess returns. In fact, $R_{\mathrm{two}}^{2}$ is slightly higher than $R_{\mathrm{one}}^{2}$. The cross-country average gap (i.e. $R_{\mathrm{two}}^{2}$ minus $R_{\text {one }}^{2}$ ) is equal to 0.012 . In other words, the two-factor model explains (on average) only an additional $1.2 \%$ of returns variation. Overall, estimation results in Table 5 and 7 suggest that changes in US macroeconomic conditions have only limited ability to explain the variation in Asian stock market excess returns. ${ }^{18}$

\section{US economic policy uncertainty and shocks}

\subsection{Methodology}

I examine the impact of Asian stock market shocks on US macroeconomic policy uncertainty, and the effects of US uncertainty shocks (in the post-crisis era) on Asian stock market prices in a VAR context. The standard mathematical representation of 
a $\operatorname{VAR}(p, k)$ system is as follows:

$$
Y_{t}=A^{1} Y_{t-1}+A^{2} Y_{t-2}+\cdots+A^{k} Y_{t-k}+W_{t}
$$

or

$$
\begin{aligned}
& \underbrace{\left[\left(\begin{array}{c}
y_{t}^{1} \\
y_{t}^{2} \\
\cdots \\
\cdots \\
y_{t}^{m} \\
\cdots \\
\cdots \\
y_{t}^{p}
\end{array}\right)\right]}_{Y_{t}}=\underbrace{\left[\left(\begin{array}{ccccc}
A_{11}^{1} & \cdots & A_{1 m}^{1} & \cdots & A_{1 p}^{1} \\
A_{21}^{1} & \cdots & A_{2 m}^{1} & \cdots & A_{2 p}^{1} \\
\cdots & \cdots & & \cdots & \cdots \\
\cdots & \cdots & & \cdots & \cdots \\
A_{m 1}^{1} & \cdots & A_{m m}^{1} & \cdots & A_{m p}^{1} \\
\cdots & \cdots & & \cdots & \cdots \\
\cdots & \cdots & & \cdots & \cdots \\
A_{p 1}^{1} & \cdots & A_{p m}^{1} & \cdots & A_{p p}^{1}
\end{array}\right)\right]}_{A^{1}} \underbrace{\left.\left[\begin{array}{c}
y_{t-1}^{1} \\
y_{t-1}^{2} \\
\cdots \\
\cdots \\
y_{t-1}^{m} \\
\cdots \\
\cdots \\
y_{t-1}^{p}
\end{array}\right)\right]}_{Y_{t-1}}
\end{aligned}
$$

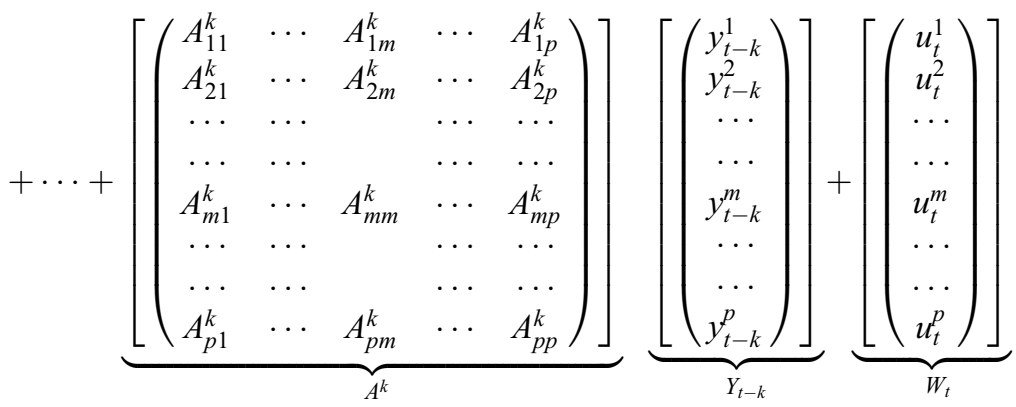

where $p$ represents the number of variables to be analyzed in the system, $k$ is the number of lags to be included in the system, $A^{1}, A^{2}, \ldots, A^{k}$ are the $p \times p$ matrices of coefficients to be estimated, and $W_{t}$ is a $p \times 1$ vector of innovations distributed as a white noise with mean zero and variance $\Omega$ (i.e. innovations are uncorrelated with their own lagged values and uncorrelated with all of the right-hand-side variables). Given that only lagged endogenous variables appear on the right-hand side of Equation (7), simultaneity does not represent an issue, and OLS deliver consistent estimates.

In this study, I estimate a set of bivariate VARs. Suppose that the excess return of one of the Asian stock markets (e.g. $\Phi$ ) and the US macroeconomic uncertainty shock (e.g. $\Phi)$ are jointly determined by a VAR and let a constant be the only exogenous variable. The bivariate VAR can then be written as follows:

or

$$
\left[\begin{array}{l}
\Psi_{t} \\
\Phi_{t}
\end{array}\right]=\left[\begin{array}{l}
c_{\Psi} \\
c_{\Phi}
\end{array}\right]+\left[\begin{array}{ll}
\alpha_{1} & \beta_{1} \\
\phi_{1} & \delta_{1}
\end{array}\right]\left[\begin{array}{l}
\Psi_{t-1} \\
\Phi_{t-1}
\end{array}\right]+\left[\begin{array}{ll}
\alpha_{2} & \beta_{2} \\
\phi_{2} & \delta_{2}
\end{array}\right]\left[\begin{array}{l}
\Psi_{t-2} \\
\Phi_{t-2}
\end{array}\right]+\left[\begin{array}{l}
u_{\Psi, t} \\
u_{\Phi, t}
\end{array}\right]
$$

$$
\begin{aligned}
& \Psi_{t}=c_{\Psi}+\alpha_{1} \Psi_{t-1}+\beta_{1} \Phi_{t-1}+\alpha_{2} \Psi_{t-2}+\beta_{2} \Phi_{t-2}+u_{\Psi, t}, \\
& \Phi_{t}=c_{\Phi}+\Psi_{1} \Psi_{t-1}+\delta_{1} \Phi_{t-1}+\phi_{2} \Psi_{t-2}+\delta_{2} \Phi_{t-2}+u_{\Phi, t},
\end{aligned}
$$

where $k=1,2, c_{\Phi}, c_{\Phi}, \alpha_{k}, \beta_{k}, \Psi_{k}$ and $\delta_{k}$ are parameters to be estimated, and $u_{\Psi, t}$ and $u_{\Phi, t}$ are the stochastic error terms (or innovations). I stress that the ordering of the variables matters for the impulse response function analysis in a Cholesky decomposition context. I assume that shocked variables (i.e. Asia stock market excess returns, in Section 6.2, and US uncertainty shocks, in Section 6.3) are ordered first in a Cholesky decomposition. 


\subsection{Asian stock markets vs. US economic policy uncertainty}

From Sections 4 and 5 we know that the Asian stock market excess returns, US macroeconomic variables and US economic policy uncertainty are stationary. Therefore, I am able to estimate a set of bivariate VARs - defined as in Equation (8) - including the Asian stock market excess return and the US economic policy uncertainty index as well as a constant. ${ }^{19}$ In my VAR scheme, lags are selected according to the Hannan-Quinn information criterion. Figure 3 reports the impulse response functions of changes in US macroeconomic policy uncertainty (black line) to an Asian stock market shock. The shaded area denotes the bootstrap confidence interval. I observe that shocks in the Asian stock market excess returns significantly affect US economic policy uncertainty. In particular, these shocks exert a negative impact such that an increase in one of the lagged Asian stock market excess returns is associated with a decrease in the level of US economic policy uncertainty. The drop is higher between two and four months after the shocks. The order of magnitude of the drop ranges from a minimum of $2.5 \%$ (Thailand) to a maximum of $4.1 \%$ (China). In other words, the log of the US economic policy uncertainty index displays a rapid fall of around $4 \%$ within two/four months, with a relatively slow recovery from three/four months after the shocks. The $90 \%$ confidence bands (shaded areas) are plotted around the impulse response functions, highlighting that this drop and the subsequent recovery is statistically significant at the $10 \%$ level. An exception is Pakistan which positively affects (i.e. it increases uncertainty) US uncertainty one month after the shock. However, the impact is negative and statistically significant from three months after the shocks. Overall, I find that a shock in the Asian stock market excess return produces a long-lasting decrease in the level of economic policy uncertainty.

\subsection{US uncertainty shocks vs. Asian stock market}

To evaluate the impact of uncertainty shocks (or rare events) on Asian stock market prices (i.e. excess returns), I estimate a range of bivariate VARs (as defined in Equation (8)) on monthly data from January 2007 to December 2011 (i.e. post-crisis era). The full set of variables employed in the VARs are stock market volatility positive shock indicator, credit and industrial production negative shock indicators, and the 10 Asian stock market excess returns. The variables in the estimation order in each bivariate VAR are (1) shock indicator and (2) Asian stock market excess return. As in Bloom (2009), the shock indicators take value 1 if a rare event occurs, and 0 otherwise. I stress that these indicators identify only extraordinary movements (i.e. rare events) in stock market volatility, consumer credit and productivity. Therefore, small ongoing fluctuations are not captured.

\subsubsection{Stock market volatility shock indicator}

Stock market rare events are chosen as those with stock market volatility more than 1.65 standard deviations above the Hodrick-Prescott detrended mean of the VIX series. (The raw undetrended series in percentage change form is plotted in Figure 7.) Formally,

$$
\text { volatility shock indicator }^{+}=\left\{\begin{array}{cc}
1 & \text { if } V I X_{t}>V \bar{I} X_{h p}+1.65 S d_{V I X} \\
0 & \text { if } V I X_{t}<V \bar{I} X_{h p}+1.65 S d_{V I X}
\end{array}\right.
$$

where $V \bar{I} X_{h p}$ is the Hodrick-Prescott detrended mean of the VIX series. Differently from previous crises, the 2007-2009 crisis has been characterized by an extremely high level of uncertainty both in the financial and in the real sectors. A marked 

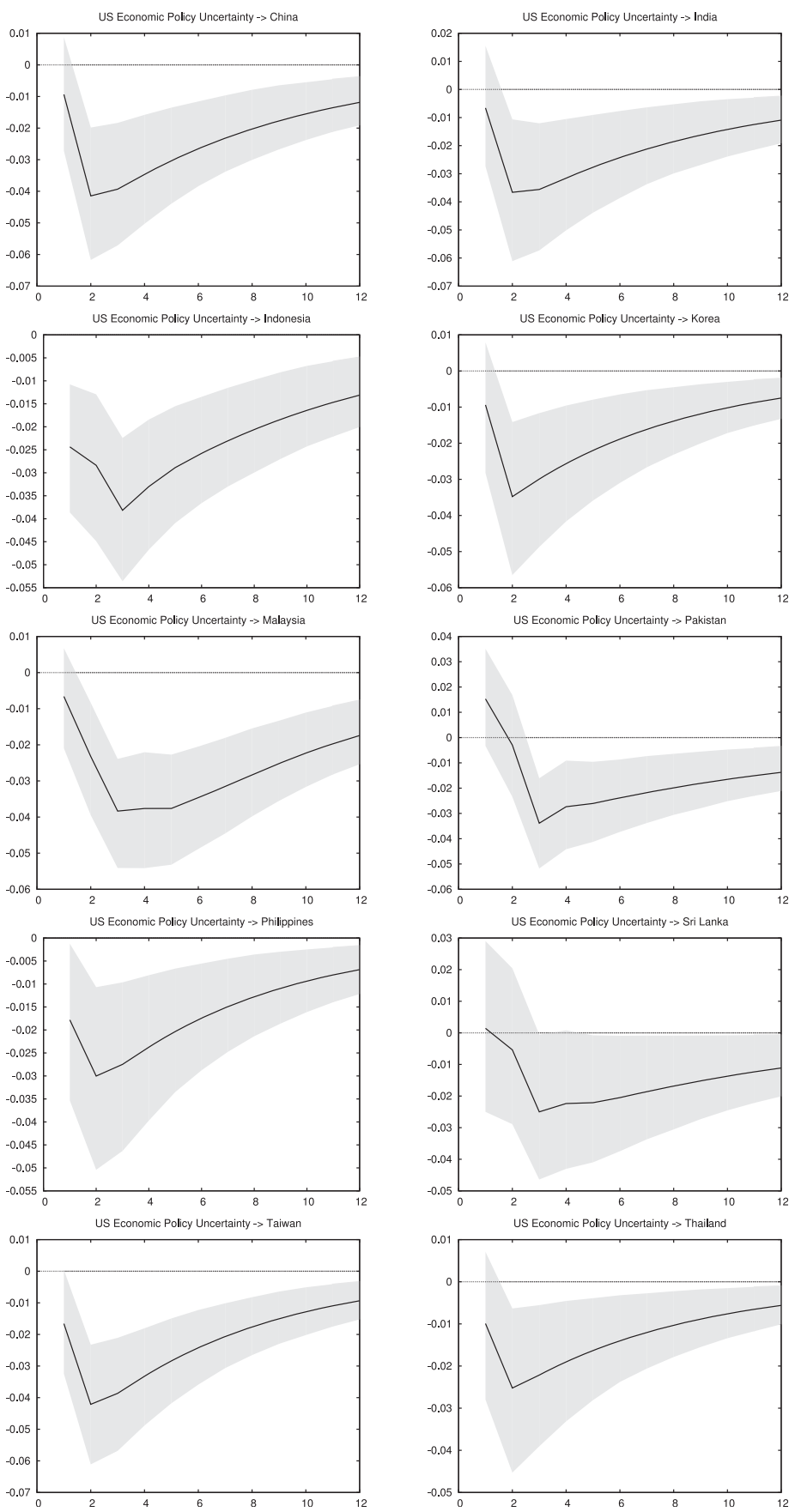

Figure 3. VAR estimations of the impact of a shock in the Asian stock market on the US economic policy uncertainty.

Notes: This figure reports the VAR Cholesky orthogonalized impulse responses of changes in US economic policy uncertainty to Asian stock market shocks. The shaded area and the black line represent $90 \%$ confidence bands and point estimates, respectively. The set of bivariate VARs are estimated including a constant (as defined in Equation (8)). Lags have been selected according to the Hanna-Quinn information criterion. Standard errors are from Newey and West (1987, 1994). Data are monthly and run from January 1988 (or later) to December 2011. 
Table 8. Subprime crisis era: US uncertainty shock dates.

United States: uncertainty shocks

Consumer credit

2008: Aug, Sep, Nov, Dec

2009: Feb, Mar, Apr, May, Jun, Jul, Aug, Sep, Oct, Nov, Dec

2010: Jan, Feb, Apr, May, Jul

2011: Aug

Industrial production

Stock market volatility

2008: Jul, Aug, Oct, Nov, Dec, Feb

2008: Sep, Oct, Nov, Dec

2009: Jan, Feb, Mar, Apr

2011: Sep

Notes: Stock market volatility, consumer credit and industrial production shock indicators are computed as defined in Equations (9)-(11). Uncertainty shocks in the US credit and production markets are based on the period January 1960-December 2011. Uncertainty shocks in the stock markets are based on the period January 1988-December 2011.

increase in uncertainty is usually produced by extraordinary events. Given the presence of a relatively high number of rare events in the subprime crisis era, I find that the VIX is 1.65 standard deviations above the Hodrick-Prescott detrended $(\lambda=14,400)$ mean of the $V I X$ series for eight consecutive months over the period January 2007-December 2012 (see Table 8). ${ }^{20}$ I argue that the subprime crisis era is unique in that it displays a relevant consecutive number of shocks, both in the stock and in the real markets. This implies that in the aftermath of the crisis, the level of economic policy uncertainty in the United States is constantly higher than in the pre-crisis era (see Figure 2).

\subsubsection{Credit market shock indicator}

Negative shocks in the consume credit market are chosen as those with consumer credit negative growth rate less than 1.65 standard deviations below the Hodrick-Prescott detrended $(\lambda=14,400)$ mean of the consumer credit growth rate series. Formally,

$$
\text { credit shock indicator }^{-}= \begin{cases}1 & \text { if } C R E D I T_{t}<C R \bar{E} D I T_{h p}-1.65 S d_{C R E D I T} \\ 0 & \text { if } C R E D I T_{t}>C R \bar{E} D I T_{h p}-1.65 S d_{C R E D I T}\end{cases}
$$

where $C R \bar{E} D I T_{h p}$ is the Hodrick-Prescott detrended mean of the consumer credit growth rate series. ${ }^{21}$ I find that the consumer credit growth rate is below the threshold defined in Equation (10) in 21 months over the period January 2007-December 2011.

\subsubsection{Production market shock indicator}

Negative shocks in the production market are chosen as those with industrial production negative growth rate less than 1.65 standard deviations below the Hodrick-Prescott detrended $(\lambda=14,400)$ mean of the industrial production growth rate series. Formally,

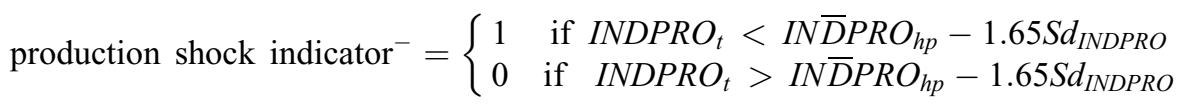

where $I N \bar{D} P R O_{h p}$ is the Hodrick-Prescott detrended mean of the industrial production growth rate series. I find that the industrial production growth rate is below the threshold defined in Equation (11) in six months over the period January 2007-December 2011. 
As noticed by Bloom (2009), uncertainty shocks tend to be generated by major economic and political shocks (e.g. Cuban missile, oil price shock and 9/11 terrorist attacks). As mentioned above, the subprime crisis era has been characterized by a relative large number of rare events, such as the Northern Rock support (September 2007), large interest rate cuts (January 2008), Lehman Brothers Chapter 11 and Troubled Asset Relief Program (October 2008), Obama election (November 2008), banking crisis (February 2009), Greek bailout (May 2010), mid-term elections (October 2010) and EU Mediterranean countries sovereign debt crisis (fall 2011). Dates of credit, production and stock market rare events (i.e. uncertainty shocks) are reported in Table 8, and can be informally observed by looking at Figure B1, which plots the US credit consumer, industrial production and stock market volatility growth rates over the period January 1988-December 2011. Do jumps in credit, industrial production and volatility have any impact on Asian stock market performances?

Figures (4)-(6) plot the impulse response functions of Asian stock market excess returns (solid black lines) to a credit, industrial production and volatility rare events shock, respectively. Main results are as follows. First, I find that uncertainty shocks affect negatively, with few exceptions, Asian stock market performances in the very short run (i.e. one month after the shock). ${ }^{22}$ Second, the negative impact of a shock in the US credit and industrial production markets on Asian stock market performances seems to be larger (i.e. around $4 \%$ ) than the impact generated by a volatility shock (i.e. around $1 \%-2 \%$ ). In addition, the $90 \%$ confidence bands around the impulse response functions (shaded areas) suggest that the one-month negative impact of a volatility shock on Asian stock market excess returns is not statistically significant (see Figure 6). In contrast, the immediate recovery, which is represented by the presence of a positive response in $t+2$ (i.e. two months after the shock), is statistically significant in most Asian stock markets. Last, the negative impact of an industrial production shock seems to last for more than one month. The response is statistically significant in the following Asian stock markets: Indonesia, Korea, Malaysia, Pakistan and Thailand (see Figure 5). It is also worth noting that the order of magnitude of a negative response generated by a shock in the production shock indicator tends to be higher than that produced by uncertainty shocks in the credit and stock markets. ${ }^{23}$ I stress that the presence of a limited number of uncertainty shocks in the US credit, production and stock markets observed in the pre-crisis sample gives rise to different results (i.e. different impulse responses). In particular, the order of magnitude of the impulse response of the Asian stock market excess return to shocks in the US credit, production or stock market volatility shock indicators tends to be extremely small and statistically insignificant. Differently, a full sample analysis and a post-crisis sample analysis produce similar impulse response functions (i.e. responses with similar orders of magnitude and durations). ${ }^{24}$ This is due to the similar number of rare events included in these two samples (full and post-crises). As suggested by Figure B1, bizarre movements in the US credit, production and stock markets take place exclusively in the post-crisis era. It turns out that the impact of uncertainty shocks on Asian stock markets' performances is higher in the subprime crisis era.

\section{Conclusion}

Emerging stock markets have attracted interest from a large number of international investors. In particular, Asian stock markets, thanks to their solid risk-return performance over the post-Asian crises period, have represented an 'insurance investment strategy' for practitioners as well as for agents. Nevertheless, a high degree of economic and financial 

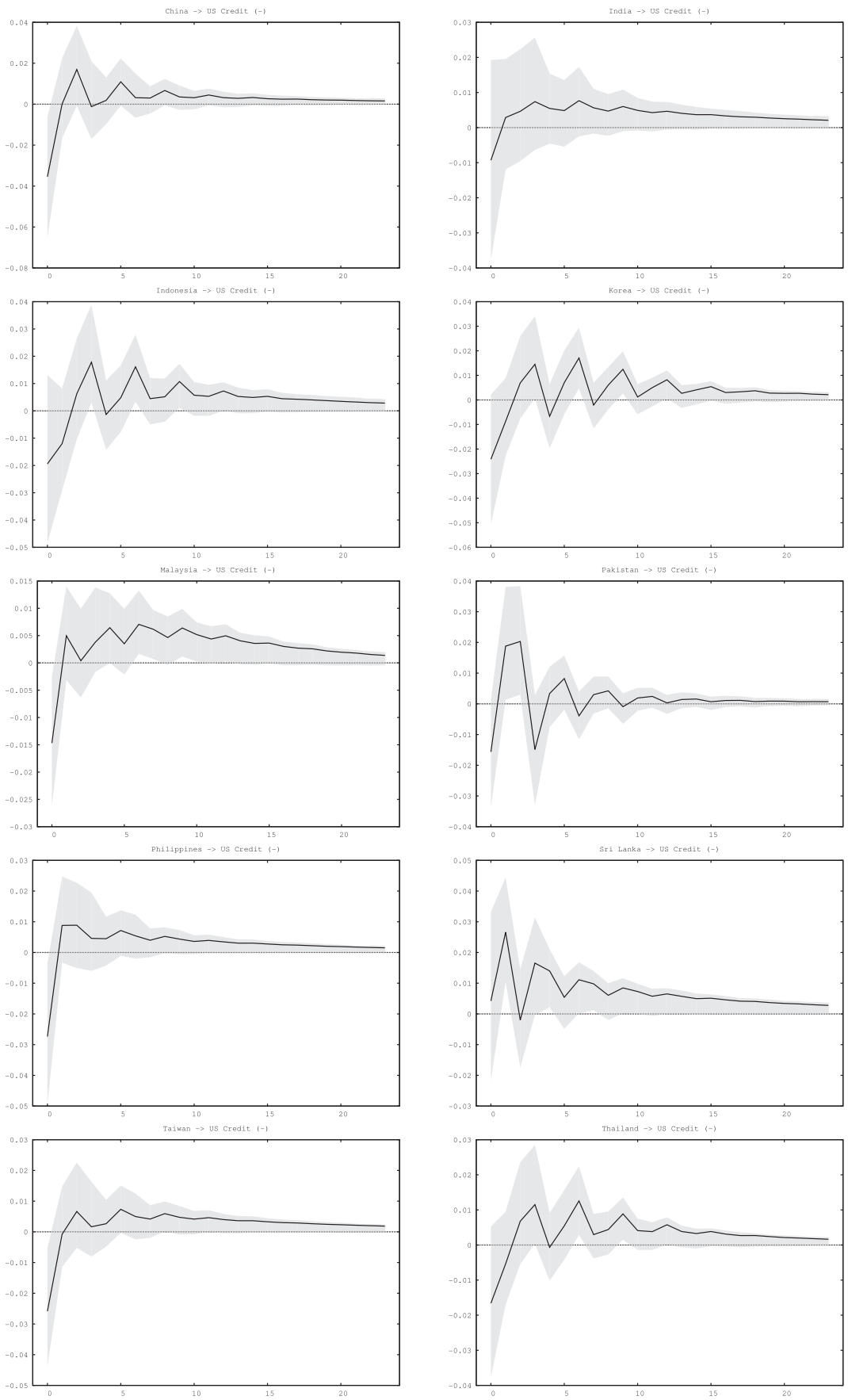

Figure 4. VAR estimations of the impact of a negative shock in the US credit market on Asian stock markets.

Notes: This figure reports the VAR Cholesky orthogonalized impulse responses of the 10 Asian stock market excess returns to a credit 'negative' shock indicator (computed as in Equation (10)). The shaded area and the black line represent $90 \%$ confidence bands (bootstrap confidence interval) and point estimates, respectively. The set of bivariate VARs are estimated including a constant (as defined in Equation (8)). Lags have been selected according to the Hanna-Quinn information criterion. Standard errors are from Newey and West $(1987,1994)$. Data are monthly and run from January 2007 to December 2011. 

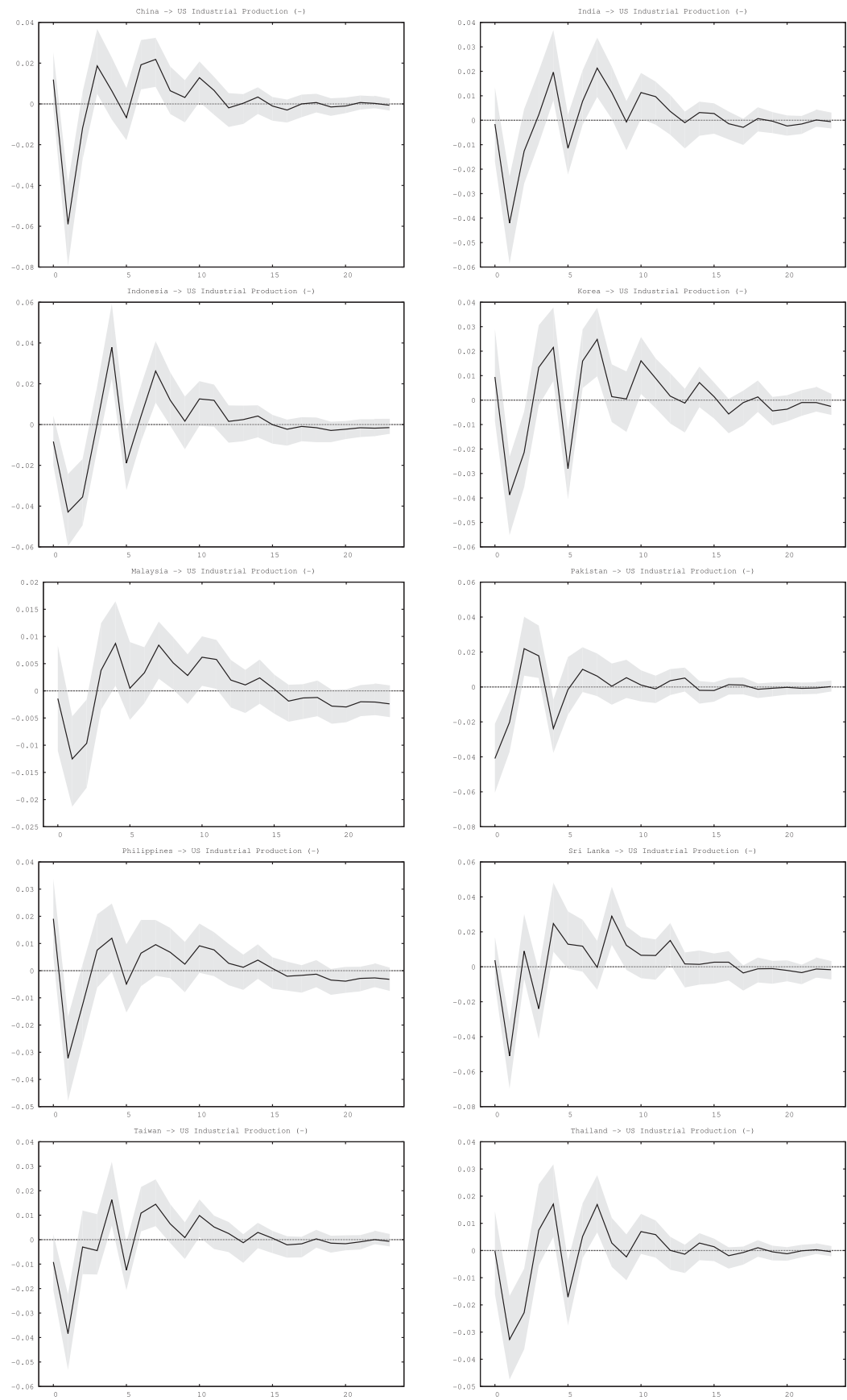

Figure 5. VAR estimations of the impact of a negative shock in the US production market on Asian stock markets.

Notes: This figure reports the VAR Cholesky orthogonalized impulse responses of the 10 Asian stock market excess returns to a production 'negative' shock indicator (computed as in Equation (11)). The shaded area and the black line represent $90 \%$ confidence bands (bootstrap confidence interval) and point estimates, respectively. The set of bivariate VARs are estimated including a constant (as defined in Equation (8)). Lags have been selected according to the Hanna-Quinn information criterion. Standard errors are from Newey and West $(1987,1994)$. Data are monthly and run from January 2007 to December 2011. 

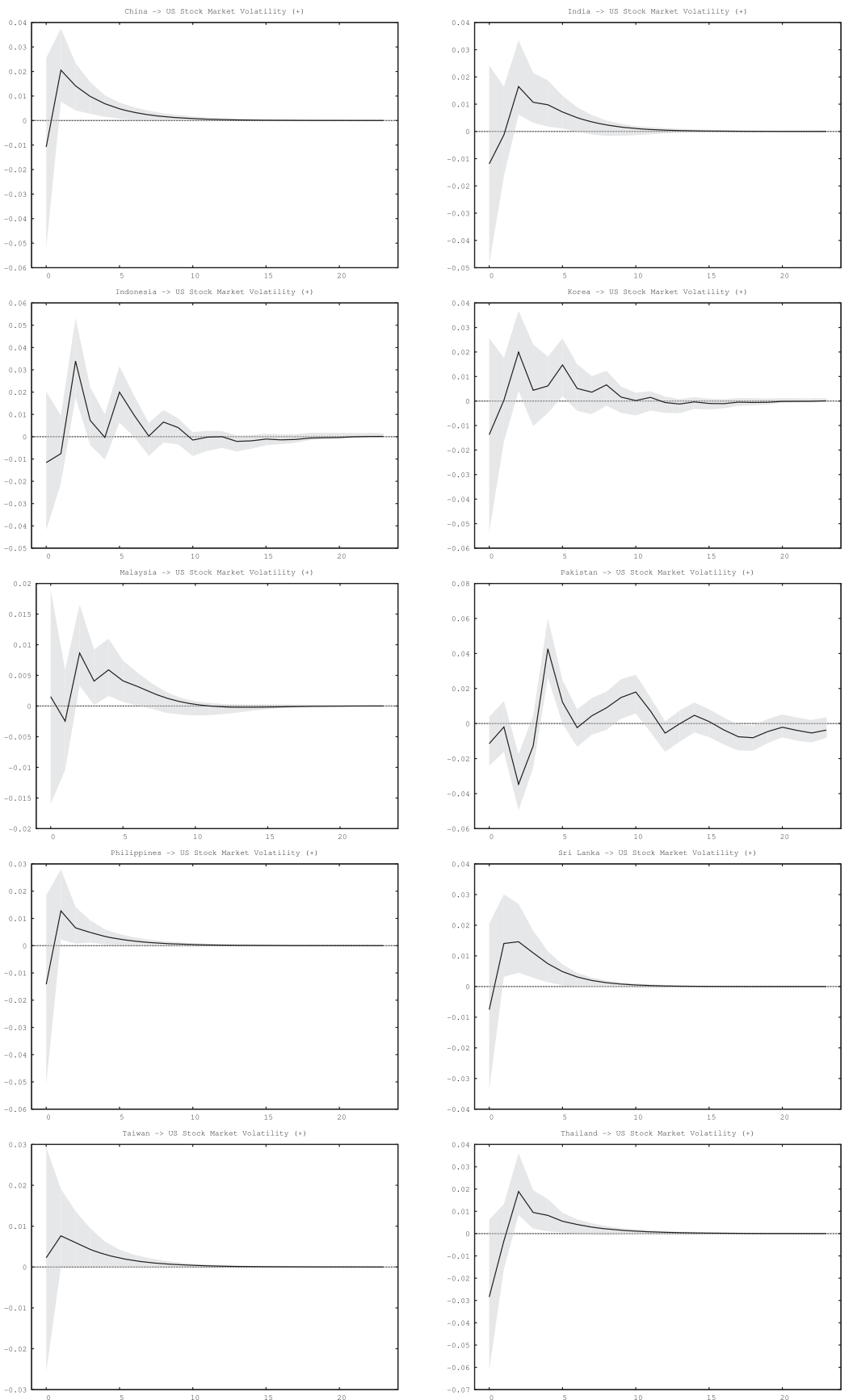

Figure 6. VAR estimations of the impact of a volatility shock in the US stock market on Asian stock markets.

Notes: This figure reports the VAR Cholesky orthogonalized impulse responses of the 10 Asian stock market excess returns to a volatility shock indicator (computed as in Equation (9)). The shaded area and the black line represent $90 \%$ confidence bands (bootstrap confidence interval) and point estimates, respectively. The set of bivariate VARs are estimated including a constant (as defined in Equation (8)). Lags have been selected according to the Hanna-Quinn information criterion. Standard errors are from Newey and West $(1987,1994)$. Data are monthly and run from January 2007 to December 2011. 
integration has affected the level of independence of international stock markets. In other words, emerging and frontier markets' performances are also influenced by global shocks.

While many studies assess the importance of domestic macroeconomic conditions on domestic stock market prices, very few works have been devoted to examine the relationship between foreign macroeconomic conditions and domestic stock markets. Following the increasing degree of co-movement between real and financial variables and financial integration across international stock markets, and the global effects of the last crisis, I examine the relationship between changes in US macroeconomic conditions and the excess return of 10 Asian stock markets. Using data from January 1988 (or later) to December 2011, and focusing on the post-subprime crisis era, I obtain three main results. First, in a Granger-causality framework, I find no evidence of a causal relationship between changes in US macroeconomic conditions and Asian stock market excess returns, suggesting that US fundamentals are not able to explain variation in monthly Asian national stock market excess returns. Second, in a bivariate VAR framework, I find that Asian stock market shocks produce a long-lasting drop in the level of economic policy uncertainty in the United States. Third, I show that negative US credit and industrial production uncertainty shocks, and positive US stock market volatility uncertainty shocks, have negatively affected Asian stock markets' performances during the 20072010 crisis.

I conclude by arguing that the results reported in this paper might have both portfolio and policy implications. On one hand, the weak explanatory power of the US macroeconomic fundamentals suggests that Asian stock market prices are still influenced by local factors. Results suggest that only rare events in the US economy affect Asian stock markets' performances. However, the effect is not long-lasting. This gives rise to long-run diversification benefits. On the other hand, a drop in the level of domestic economic policy uncertainty - generated by foreign stock market shocks - might affect the behavior of monetary and fiscal authorities. In particular, a higher level of macroeconomic stability might induce them to be more aggressive.

\section{Acknowledgements}

I thank Mark J. Holmes (the editor) and three anonymous referees. I also thank, without implication, Antonio Barbera and Nicoló Zanotto for their advice on macroeconomic data. All remaining errors are of course my own.

\section{Notes}

1. Asian financial crisis dates: Indonesia (1997-2002), Malaysia (1997-2001), Philippines (1983-1987, 1997-2002), Sri Lanka (1989-1993) and Thailand (1983-1987, 1997-2002).

2. For a detailed discussion on the dynamics of emerging stock market prices in the pre- and post-subprime crisis eras, see Donadelli (2013).

3. Throughout the paper, I use the terms macroeconomic variables, macroeconomic fundamentals or fundamentals interchangeable.

4. I refer to the period January 2007-December 2011. As of January 2007, Ownit Mortgage Solutions Inc. files for Chapter 11 and American Freedom Mortgage, Inc. files for Chapter 7 protection.

5. See Henry (2000) and Bekaert, Harvey, and Lundblad (2003), for a detailed discussion on equity market liberalizations in Asia. For a detailed discussion on the presence of structural breaks in the dynamics of the US investment in the Asian stock markets, see Bekaert and Harvey (2000). 
6. Data availability: (1) Indonesia, Korea, Malaysia, Philippines, Taiwan and Thailand MSCI TRIs are available from December 1987; and (2) China, India, Pakistan and Sri Lanka MSCI TRIs are available from December 1992.

7. The one-month T-bill rate is publicly available at http://mba.tuck.dartmouth.edu/pages/ faculty/ken.french/.

8. Differently from Narayan and Narayan (2012), my 'monthly frequency analysis' does not impose the use of a relatively low number of global risk factors.

9. The selected variables are consistent with the selection procedure embodied in Autometrics (see Doornik, 2009). The procedure has been used to build a novel global leading indicator for Kalis Capital. The views expressed here are those of the author and not necessarily those of Kalis Capital.

10. These works build a global economic indicator aimed at capturing global cyclical swings. In other words, a global leading indicator should provide early signals on turning points in the global cycle. For example, the global leading indicator of Goldman Sachs includes a business confidence aggregate, a consumer confidence aggregate, and the US initial jobless claims as well as other international trade measures.

11. The results from the augmented Dickey-Fuller test are available upon request.

12. The regression in Equation (5) is also estimated assuming different lag structures (e.g. all US macroeconomic variables measured contemporaneously and at $t-2$ ). Similar results are obtained and available upon request.

13. Bilson et al. (2001) and Donadelli (2013) estimate a multiple beta model with a similar lag structure.

14. In a conditional two-factor model, Donadelli and Prosperi (2012) obtain similar results.

15. Under mild statistical assumptions, the Generalized Method of Moments (GMM) applies, and estimated values are similar to those obtained via OLS estimations. GMM estimation results, where a constant and the US macroeconomic indicators are used as instruments, are available upon request.

16. Results are clearly sample-sensitive. For example, Donadelli (2013) observes that the predictive power of the global risk factors is increasing over time. I stress that a dynamic analysis is beyond the scope of the paper.

17. For a detailed discussion on the construction of the US economic policy uncertainty index, see Baker et al. (2013).

18. Note that a multi-factor model where the US economic policy uncertainty is added as an extra risk factor to Equation (5) produces similar results.

19. I stress that one may use a structural VAR even if the variables employed in the analysis are non-stationary. As discussed in Sims, Stock, and Watson (1990) and Hamilton (1994), the estimated coefficients of the VAR with possibly non-stationary variables are consistent and the asymptotic distribution of individual estimated parameters is standard (i.e. normal distribution). In addition, the impulse response functions are consistent estimators of the true impulse-response functions except in long run (Phillips, 1996).

20. Bloom (2009) finds 17 stock market volatility shocks over the period July 1963-June 2008 (i.e. only one shock is associated with the subprime crisis).

21. With variables expressed in percentage change form, the difference between the mean of the detrended series and the mean of the raw series is small.

22. Uncertainty shocks are defined as shocks on the credit, production and stock market volatility shock indicators.

23. This is in line with recent international business cycle studies showing that there is little relation between credit and financial linkages that economies have with the United States and the decline in their GDP growth rate and asset prices during the 2008-2009 global demand collapse (Kalemli-Ozcan, Papaioannou, \& Perri, 2013; Kamin \& Pounder, 2010; Rose \& Spiegel, 2010).

24. The full set of impulse response functions is available upon request.

\section{References}

Antonakakis, N., Chatziantoniou, I., \& Filis, G. (2012). Dynamic co-movements between stock market returns and policy uncertainty (MPRA Paper No. 42905). Retrieved from: http://mpra.ub. uni-muenchen.de/id/eprint/42905 
Araujo, E. (2009). Macroeconomic shocks and the co-movement of stock returns in Latin America. Emerging Markets Review, 10(4), 331-344.

Baker, S., Bloom, N., \& Davis, S. (2013). Measuring economic policy uncertainty (Working Paper Series). Redwood City, CA: Stanford University Press.

Bekaert, G., \& Harvey, C.R. (2000). Capital flows and the behavior of emerging equity market returns. In S. Edwards (Ed.), Capital flows and the emerging economies: Theory, evidence and controversies (pp. 159-194). Chicago, IL: University of Chicago Press..

Bekaert, G. Harvey, C.R., \& Lundblad, C. (2003). Equity market liberalization in emerging markets. The Journal of Financial Research, 26(3), 275-299.

Bilson, C.M., Brailsford, T.J., \& Hooper, V.J. (2001). Selecting macroeconomic variables as explanatory factors of emerging stock market returns. Pacific-Basin Finance Journal, 9(4), 401-426.

Binswanger, M. (2004). How important are fundamentals? Evidence from a structural VAR model for the stock markets in the US, Japan and Europe. Journal of International Financial Markets, Institutions and Money, 14(2), 185-201.

Bloom, N. (2009). The impact of uncertainty shocks. Econometrica, 77(3), 623-685.

Chambet, A., \& Gibson, R. (2008). Financial integration, economic instability and trade structure in emerging markets. Journal of International Money and Finance, 27, 654-675.

Chen, N., Roll, R., \& Ross, S.A. (1986). Economic forces and the stock market. Journal of Business, $59,383-403$.

Daly, K., \& Fayyad, A. (2011). The impact of oil price shocks on stock market returns: Comparing GCC countries with the UK and USA. Emerging Markets Review, 12(1), 61-78.

de Jong, F., \& de Roon, F.A. (2005). Time varying market integration and expected returns in emerging markets. Journal of Financial Economics, 78(3), 583-613.

Donadelli, M. (2013). Global integration and emerging stock market excess returns. Macroeconomics and Finance in Emerging Market Economies, 6(2), 1-36.

Donadelli, M., \& Persha, L. (2014). Understanding emerging market equity risk premia: Industries, governance and macroeconomic policy uncertainty. Research in International Business and Finance, 30, 284-309.

Donadelli, M., \& Prosperi, L. (2012). On the role of liquidity in emerging markets stock prices. Research in Economics, 66(4), 320-348.

Doornik, J.A. (2009). Autometrics. In J.L. Castle \& N. Shepard (Eds.), The methodology and practice of econometrics (pp. 88-121). Oxford: Oxford University Press.

Ferson, W., \& Harvey, C.R. (1994). Sources of risk and expected returns in global equity markets. Journal of Banking and Finance, 18, 775-803.

Granger, C.W.J. (1969). Investigating causal relations by econometric models and cross-spectral methods. Econometrica, 37(3), 424-438.

Grootveld, H., \& Salomons, R. (2003). The equity risk premium: Emerging vs. developed markets. Emerging Markets Review, 4(2), 121-144.

Hamilton, J.D. (1994). Time series analysis. Princeton, NJ: Princeton University Press.

Harvey, C.R. (1995). Predictable risk and returns in emerging markets. Review of Financial Studies, $8,773-816$.

Henry, P. (2000). Stock market liberalization, economic reform and emerging market equity prices. Journal of Finance, 55, 529-564.

International Finance Corporation. (1999). The IFC indexes: Methodology, definitions and practices. Washington, DC: International Finance Corporation.

Jagannathan, R., McGrattan, E.R., \& Scherbina, A. (2000). The declining U.S. equity premium. Federal Reserve Bank of Minneapolis Quarterly Review, 24(4), 3-19.

Kalemli-Ozcan, S., Papaioannou, E., \& Perri, F. (2013). Global banks and crisis transmission. Journal of International Economics, 89(2), 495-510.

Kamin, S.B., \& Pounder De Marco, L. (2010). How did a domestic slump turn into a global financial crisis? (FED International Finance Discussion Paper n. 994). Retrieved from: http://www. federalreserve.gov/Pubs/Ifdp/2010/994/default.htm

Lee, C., Chen, M., \& Chang, C. (2013). Dynamic relationships between industry returns and stock market returns. The North American Journal of Economics and Finance, 26, 119-144.

Narayan, P.K., \& Narayan, S. (2012). Do US macroeconomic conditions affect Asian stock markets? Journal of Asian Economics, 23(6), 669-679. 
Newey, W.K., \& Kenneth, W.D. (1987). A simple, positive semi-definite, heteroskedasticity and autocorrelation consistent covariance matrix. Econometrica, 55(3), 703-708.

Newey, W.K., \& Kenneth, W.D. (1994). Automatic lag selection in covariance matrix estimation. Review of Economic Studies, 61(4), 631-654.

Phillips, P.C.B. (1996). Impulse response and forecast error variance asymptotics in nonstationary VARs. Journal of Econometrics, 83, 21-56.

Pukthuanthong, K., \& Roll, R. (2009). Global market integration: An alternative measure and its application. Journal of Financial Economics, 92(2), 214-232.

Rapach, D.E. (2001). Macro shocks and real stock prices. Journal of Economics and Business, 53 (1), 5-26.

Rose, A., \& Spiegel, M. (2010). The causes and consequences of the 2008 crisis: International linkages and American exposure. Pacific Economic Review, 15, 340-363.

Sharma, S.C., \& Wongbangpo, P. (2002). Stock market and macroeconomic fundamental dynamic interactions: ASEAN-5 countries. Journal of Asian Economics, 13(1), 27-51.

Sims, C.A., Stock, J.H., \& Watson, M.W. (1990). Inference in linear time series models with some unit roots. Econometrica, 58, 113-144.

\section{Appendix 1. US economic policy uncertainty}

Table A1 Unit root test results for the log of the US economic policy uncertainty index (USEcPolUn). The monthly US economic policy uncertainty index is from Baker et al. (2013) and is publicly available at http://www. policyuncertainty.com/.

\begin{tabular}{lr}
\hline Series & $\begin{array}{c}\text { Level } \\
A D F_{\mu}\end{array}$ \\
\hline $\log (\mathrm{USEcPolUn})$ & $(-3.589 * * *)$ \\
\hline $\begin{array}{l}\text { Notes: The augmented Dickey-Fuller test }\left(A D F_{\mu}\right) \text { includes a constant. The } 10 \%, 5 \% \text { and } \\
1 \% \text { critical values are }-2.572,-2.872 \text { and }-3.455, \text { respectively. }{ }^{* * *},{ }^{* *}, *\end{array}$ \\
nificance at $1 \%, 5 \%$ and $10 \%$ level, respectively.
\end{tabular}




\section{Appendix 2. United States: stylized facts}

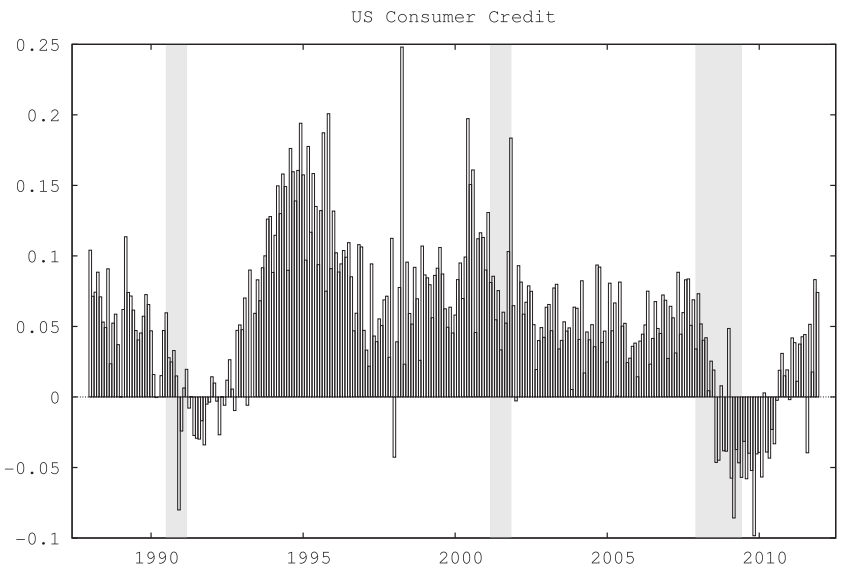

US Industrial Production

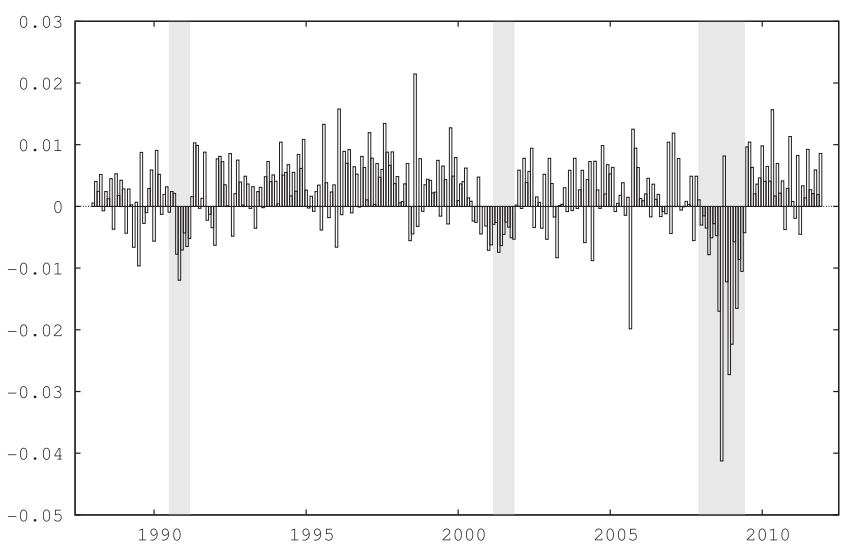

US Stock Market Volatility

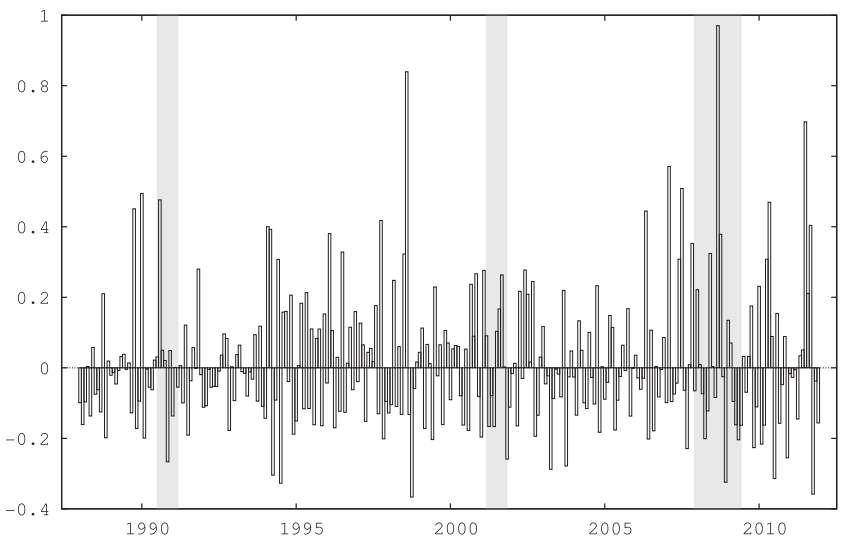

Figure B1. Movements in the US credit, production and stock markets.

Notes: This figure reports the growth rate of the US consumer credit (CRED), industrial production and capacity utilization index (INDPRO), and stock market volatility $(V I X)$. The shaded vertical bars denote NBER-dated recessions. Data run from January 1988 to December 2011.

Source: Fed St. Louis and Datastream. 